\title{
Dietary Caffeine Synergizes Adverse Peripheral and Central Responses to Anesthesia in Malignant Hyperthermia Susceptible Mice ${ }^{\mathbb{\$}}$
}

\author{
Monica Aleman, Rui Zhang, Wei Feng, Lihong Qi, Jose R. Lopez, Chelsea Crowe, \\ Yao Dong, Genady Cherednichenko, and Isaac N. Pessah
}

Department of Molecular Biosciences, School of Veterinary Medicine (R.Z., W.F., J.R.L., Y.D., G.C., I.N.P.), Department of Medicine and Epidemiology, The William R. Pritchard Veterinary Medical Teaching Hospital, School of Veterinary Medicine (M.A., C.C.), and Department of Public Health Sciences, School of Medicine, School of Medicine (L.Q.), University of California, Davis, California

Received January 6, 2020; accepted July 31, 2020

\section{ABSTRACT}

Ryanodine receptor $(R Y R)$ mutations confer stress-triggered malignant hyperthermia $(\mathrm{MH})$ susceptibility. Dietary caffeine (CAF) is the most commonly consumed psychoactive compound by humans. CAF-triggered $\mathrm{Ca}^{2+}$ release and its influences on skeletal muscle contractility are widely used as experimental tools to study RYR function/dysfunction and diagnose $\mathrm{MH}$ susceptibility. We hypothesize that dietary CAF achieving blood levels measured in human plasma exacerbates the penetrance of $R Y R 1 \mathrm{MH}$ susceptibility mutations triggered by gaseous anesthetic, affecting both central and peripheral adverse responses. Heterozygous R163C-RYR1 (HET) MH susceptible mice are used to investigate the influences of dietary CAF on both peripheral and central responses before and after induction of halothane (HAL) maintenance anesthesia under experimental conditions that maintain normal core body temperature. HET mice receiving CAF (plasma CAF $893 \mathrm{ng} / \mathrm{ml}$ ) have significantly shorter times to respiratory arrest compared with wild type, without altering blood chemistry or displaying hyperthermia or muscle rigor. Intraperitoneal bolus dantrolene before HAL prolongs time to respiratory arrest. A pilot electrographic study using subcutaneous electrodes reveals that dietary CAF does not alter baseline electroencephalogram (EEG) total power, but significantly shortens delay to isoelectric EEG, which precedes respiratory and cardiac arrest. CAF $\pm \mathrm{HAL}$ are studied on RYR1 single-channel currents and HET myotubes to define molecular mechanisms of gene-by-environment synergism. Strong pharmacological synergism between CAF and HAL is demonstrated in both single-channel and myotube preparations. Central and peripheral nervous systems mediate adverse responses to HAL in a HET model of MH susceptibility exposed to dietary CAF, a modifiable lifestyle factor that may mitigate risks of acute and chronic diseases associated with RYR1 mutations.

\section{SIGNIFICANCE STATEMENT}

Dietary caffeine at a human-relevant dose synergizes adverse peripheral and central responses to anesthesia in malignant hyperthermia susceptible mice. Synergism of these drugs can be attributed to their actions at ryanodine receptors.

\section{Introduction}

Mutations in the gene that encodes ryanodine receptor $(R Y R)$ 1 are known to cause fulminant malignant hyperthermia $(\mathrm{MH})$, an acute, potentially fatal, pharmacogenetic disease triggered

This work was supported by National Institutes of Health National Institute of Environmental Health Sciences [Grants ES R014901 and P42 ES004699], National Science Foundation [Grant 1840842], and National Institutes of Health National Institute of Arthritis and Musculoskeletal Sciences [Grant P01 AR052354]. The research was also supported by the University of California, Davis, Equine and Comparative Neurology Research Group (M.A.).

Current affiliation for J.R.L.: Department of Research, Mount Sinai Medical Center, Miami, Florida.

M.A.and R.Z. contributed equally.

https://doi.org/10.1124/mol.120.119412.

S This article has supplemental material available at molpharm. aspetjournals.org. perioperatively by the use of halogenated volatile anesthetics or depolarizing muscle relaxants (Zhou et al., 2014). Clinical manifestations of a fulminant crisis include extreme hypercapnia, metabolic and respiratory acidosis, hyperlactatemia, hyperthermia, profuse sweating, tachycardia, tachypnea, muscle rigidity, and ultimately death (Zhou et al., 2014; Litman et al., 2018). In food and companion animals (McCarthy et al., 1990; Fujii et al., 1991; Roberts et al., 2001; Aleman et al., 2004), as well as murine models that express human $\mathrm{MH}$ susceptibility mutations in $R Y R 1$, exertional and environmental heat stress is also known to trigger a fulminant MH crisis (Chelu et al., 2006; Yang et al., 2006; Yuen et al., 2012; Lopez et al., 2018). Patients with mutations within RYR 1 and 20 additional loci are linked to susceptibility to myopathic injury throughout the lifespan (Jungbluth et al., 2018). However, the clinical onset

ABBREVIATIONS: ADR, adverse drug response; $A U C$, area under the curve; $A \mathrm{UC}_{\mathrm{Bza}}$, benzotriazole peak $\mathrm{AUC}$; $\mathrm{AUC} \mathrm{CAF}_{\mathrm{C}}, \mathrm{CAF}$ peak $\mathrm{AUC}$; $\mathrm{BLM}$, bilayer lipid membrane; $\mathrm{CAF}$, caffeine; $\mathrm{CaV}_{1.1}$, voltage-gated $\mathrm{Ca}^{2+}$ channel; $\mathrm{DAN}$, dantrolene; $\mathrm{ECG}$, electrocardiogram; EEG, electroencephalogram; EEG $_{\text {TP }}$, EEG total power $(\mu \mathrm{V})$; FDR, false discovery rate; FMH, fulminant MH; HAL, halothane; HET, heterozygous for R163C-RYR1; HPLC, highperformance liquid chromatography; isoEEG, isoelectric EEG; IVCT, in vitro contracture testing; $\mathrm{MH}$, malignant hyperthermia; $\mathrm{P}_{\mathrm{o}}$, open probability; RYR, ryanodine receptor; SR, sarcoplasmic reticulum; UC Davis, University of California, Davis; VEH, vehicle; WT, wild type. 
and severity of histopathological damage vary broadly among individual mutation carriers, and their relationship to RYR1 genotype is complex, suggesting medical, lifestyle, and environmental factors may contribute not only to the initiation of fulminant $\mathrm{MH}$ during the perioperative period but also to enhanced susceptibility to the promotion of chronic myopathic injury through unknown mechanisms (Rosenberg et al., 2015; Voermans et al., 2016).

$\mathrm{MH}$ susceptibility is generally viewed through the lens of rare skeletal muscle diseases with the clinical diagnosis of $\mathrm{MH}$ susceptibility relying on in vitro contracture testing (IVCT) performed on skeletal muscle biopsies from suspected probands to ascertain enhanced sensitivity to caffeine (CAF)- and halothane (HAL)-induced muscle contracture (Hopkins et al., 2015). Although a strong linkage exists with the RYR1 locus on chromosome 19, the large number of expressed genomic $R Y R 1$ variants ( $>300)$ known to occur in the human population, as well as suggestive linkage with six additional loci, has made genetic screening impractical as a first-line diagnosis (Hopkins et al., 2015). As such, the IVCT remains the gold standard for the diagnosis of MH in human medicine (Zhou et al., 2014; Hopkins et al., 2015; Litman et al., 2018). When feasible, a positive IVCT is confirmed by genetic screening of the RYR1 locus. Recent estimates of RYR1 genotypephenotype (IVCT) concordance range as low as $34 \%$ in Australian studies (Gillies et al., 2008; Gillies et al., 2015) to $52 \%$ in a US study (Brandom et al., 2013) to as high as $76 \%$ in a primarily European Caucasian cohort drawn from the United Kingdom (Miller et al., 2018). However, results from a recent multicenter case control study of 229 genotypepositive subjects with previously recorded exposure to trigger anesthetics found an overall penetrance for the analyzed RYR1 mutations of only 40.6\% (Ibarra Moreno et al., 2019). Lower than expected genotype-phenotype concordance, including discordance within a family between a functionally relevant $R Y R 1$ variant and the IVCT phenotype, has been attributed to low penetrance of many $R Y R 1$ variants in the absence of other genetic risk factors or errors in either genotyping or phenotyping (Adeokun et al., 1997; Robinson et al., 2003; Miller et al., 2018), or nongenetic risk factors, such as age and sex (Ibarra Moreno et al., 2019).

Considering the pharmacogenetic nature of $\mathrm{MH}$ susceptibility and our dependence of its diagnosis on muscle sensitivity to CAF and/or HAL (i.e., the IVCT), whether humanrelevant plasma concentrations of dietary CAF may or may not influence adverse drug responses (ADRs) in vivo has not been previously considered. CAF is the most widely consumed psychoactive compound worldwide, with $85 \%$ of US adults consuming an average intake of $200-400 \mathrm{mg} /$ day, mainly through caffeinated beverages (Barone and Roberts, 1996; Mitchell et al., 2014). An English study of 600 medical outpatients reported a mean plasma caffeine concentration of $2.1 \mathrm{mg} / \mathrm{l}(10.9 \mu \mathrm{M})$ (Smith et al., 1982) which is consistent with more recent levels measured in US nonsmokers (9.9-17.4 $\mu \mathrm{M})$ and smokers $(2.8-10.1 \mu \mathrm{M})$, levels that are positively correlated with consumption (de Leon et al., 2003). In the latter study, $99 \%$ of study participants had detectable caffeine with a mean caffeine intake of $3.02 \mathrm{mg} / \mathrm{kg}$ per day. Although $\mathrm{CAF}$ consumption through diet has generally been considered safe to human health, recent studies with animal models and from human epidemiology suggest possible adverse influences on genetically susceptible populations (Cornelis et al., 2006;
Palatini et al., 2009; Yang et al., 2010; Ding et al., 2014; Findley et al., 2019; Korekar et al., 2019; Zhou and Hypponen, 2019).

Here, we address three biologically interrelated questions using in vivo exposures, cellular imaging, and single-channel voltage clamp approaches to assess the influences of dietary $\mathrm{CAF}$, at levels well within those currently measured in plasma of human populations worldwide, on the penetrance of $\mathrm{MH}$ susceptibility to volatile gaseous anesthetic such as HAL and its currently used alternatives. We hypothesize that dietary CAF achieving blood levels measured in human plasma exacerbates the penetrance of $R Y R 1 \mathrm{MH}$ susceptibility mutations triggered by gaseous anesthetic, affecting both central and peripheral adverse responses. We further address whether dantrolene (DAN), currently the standard of care treatment to mitigate the onset and progression of fulminant $\mathrm{MH}$ (Rosen et al., 2019), will mitigate the synergistic effects of CAF during anesthesia. Using the heterozygous R163C (HET) MH susceptible mouse model, one of the more common mutations confirmed to cause MH susceptibility in humans, herein we provide direct evidence that dietary CAF profoundly influences both peripheral and central cortical responses that are synergistic to those of HAL. Compared with wild-type mice, MH susceptible mice do not show different basal electroencephalogram (EEG) total power $\left(\mathrm{EEG}_{\mathrm{TP}}\right)$ in the absence and presence of dietary CAF. However, the CAFexposed HET mice show shorter times to achieve isoelectric EEG (isoEEG) and respiratory and cardiac arrest under HAL anesthesia in the absence of fulminant hyperthermia or muscle rigidity. The synergism between CAF and HAL is demonstrated in myotubes in vitro and can be directly attributed to their synergistic influences on alteration of RYR1 channel function.

These results are the first to identify peripheral and central nervous system contributions to MH susceptibility and demonstrate that a common modifiable lifestyle factor, caffeine consumption, significantly modifies the penetrance of a common RYR1 mutation.

\section{Materials and Methods}

Animals for In Vivo Studies. All animal dosing, terminal experiments, euthanasia, and tissue and blood collection procedures were conducted under protocols approved by the Institutional Animal Care and Use Committee (18094) at the University of California, Davis (UC Davis; Davis, CA). All animals were C57BL6/J maintained in a vivarium with constant temperature and humidity with a 12 : 12 light-dark cycle. Animals were provided with Mouse Diet 20 (PicoLab) and autoclaved drinking water provided by the UC Davis animal facility ad libitum. Well trained, certified staff were responsible for the periodic time-mating of breeding R163C-RYR1 HET and wild-type (WT) trios and provided mice in vivo experiments. All the animal-related procedures met the requirements of the guidelines of Animal Use and Care of the National Institutes of Health and were approved by the UC Davis Animal Use and Care Committee.

Two separate cohorts of adult mice (4-6 months of age) were used for in vivo dietary caffeine studies. Both male and female WT and R163C-RYR1 HET mice were included in the dietary caffeine studies receiving either vehicle (+VEH; water) or dietary caffeine $(+\mathrm{CAF})$ with (+DAN) or without ( $-\mathrm{DAN})$ a single dose of dantrolene $(2.5 \mathrm{mg} / \mathrm{kg}$ i.p. $)$ prior to commencing anesthesia. HET mice were generated with a knock-in mutation-targeting vector as described previously and bred into the C57BL/6 background (The Jackson Laboratory) after the 
genotype was confirmed (Yang et al., 2006; Cherednichenko et al., 2008; Feng et al., 2011; Giulivi et al., 2011; Truong and Pessah, 2019).

For the main study that monitored respiration (cohort 1), 10-16 mice were randomly assigned to one of eight treatment groups as follows: WT+VEH $(n=13), \mathrm{WT}+\mathrm{CAF}(n=16), \mathrm{HET}+\mathrm{VEH}(n=13)$, $\mathrm{HET}+\mathrm{CAF}(n=14), \mathrm{HET}+\mathrm{VEH}+\mathrm{DAN}(n=11)$, and HET $+\mathrm{CAF}+\mathrm{DAN}$ $(n=10)$. Approximately $50 \%$ males and females were included in each group. Additional mice were randomly assigned to four treatment groups (WT+VEH; WT+CAF; HET+VEH; HET+CAF) to measure possible influences of the dietary CAF protocol on baseline blood chemistry without subjecting then to maintenance HAL.

A follow-on pilot study with a smaller number of mice (cohort 2) was undertaken to replicate findings in cohort 1 using electrographic monitoring. Power analysis based on effect sizes obtained with cohort 1 indicated that $n=3-4$ mice per treatment/genotype group was sufficient to ascertain temporal differences across genotype and treatment groups for cortical EEG, respiratory rate, and heart rate with an $80 \%$ chance of a value of $P=0.05$.

Mice were randomly assigned to six treatment groups as follows: $\mathrm{WT}+\mathrm{VEH}(n=3), \mathrm{WT}+\mathrm{CAF}(n=3), \mathrm{HET}+\mathrm{VEH}(n=3), \mathrm{HET}+\mathrm{CAF}$ $(n=3), \mathrm{HET}+\mathrm{VEH}+\mathrm{DAN}(n=3)$, and HET+CAF+DAN $(n=4)$ and instrumented for electrographic recordings as described below.

Chemicals and Solutions. CAF ( $\geq 99.0 \%$, CAS 58-08-2) and HAL (2-bromo-2-chloro-1,1,1-trifluoroethane, $\geq 99.0 \%$, CAS 151-67-7) were obtained from Sigma-Aldrich (St. Louis, MO). Dantrolene sodium (Dantrium Intravenous, CAS 14663-23-1) was obtained as a lyophilized mixture with mannitol and sodium hydroxide from Ben Venue Laboratories (Bedford, OH). Solutions of $0.05 \% \mathrm{HAL}$ ( $4.75 \mathrm{mM}$ ), in the presence or absence of CAF, were prepared from a neat stock $(9.5 \mathrm{M}$ containing $0.01 \%$ thymol) diluted 1:2000 in Locke's buffer immediately before each cellular experiment. All solutions were kept in sealed amber tubes protected from light. For single-channel voltage clamp experiments, CAF, HAL, or the combination were made as $10 \times$ working stocks in amber tubes and introduced directly into the cis chamber solution (see below). All dilution stocks were made and used on the day of each experiment. All HAL solutions were thoroughly dissolved in buffer with sonication before use.

Oral CAF Dosing and Blood Levels. Using the assumption that the average human weighs $70 \mathrm{~kg}$ and the average mouse weighs $25 \mathrm{~g}$, this daily intake is equivalent to $0.143 \mathrm{mg} /$ day in mice based on a $400 \mathrm{mg}$ daily intake in humans, equivalent to $5.7 \mathrm{mg} / \mathrm{kg}$ per day in mice. Following Kleiber's law (Kleiber, 1947), which states that an organism's total metabolic rate is equal to the three-fourth power of its mass and, accordingly, its specific metabolic rate (metabolic rate per unit of mass) is equal to the negative one-fourth power of its mass, we calculated that a $25 \mathrm{~g}$ mouse is $\sim 7.2$ times more metabolically active compared with a $70 \mathrm{~kg}$ human. Pilot studies were performed to identify a CAF oral dose that would result in blood levels similar to those measured in human blood of CAF consumers based on the mean daily CAF intake of 200-400 mg reported previously by others (Smith et al., 1982; Barone and Roberts, 1996; de Leon et al., 2003; Mitchell et al., 2014). Therefore, adjusting for allometric and metabolic differences and assuming a mouse drinks $5 \mathrm{ml}$ of water a daily, we defined the target dose of $0.2 \mathrm{mg} / \mathrm{ml}$ of CAF in drinking water. Mice were maintained on $\mathrm{VEH}$ or $\mathrm{CAF}$ ad libitum for $\geq 7$ days to ensure a steadystate CAF concentration in the circulation. Both VEH and CAF dosing solutions were filtered through $0.2 \mu \mathrm{m}$ filters after preparation. For both genotypes, mice were randomly assigned to receive either VEH (5\% sucrose in water) or CAF $(0.2 \mathrm{mg} / \mathrm{ml}$ with $5 \%$ sucrose in water) through drinking water.

All plasma samples (standards and unknowns) were processed together to ensure consistency and to minimize errors. Fresh stocks of caffeine and benzotriazole were prepared in ultrapure water. Using caffeine-free plasma pooled from a set of naïve mice, standards were created by spiking samples of the blank plasma (100 $\mu \mathrm{l}$ each) with known concentrations of caffeine $(0-250 \mu \mathrm{M})$. All standards and unknowns ( $100 \mu \mathrm{l}$ each) were then spiked with the internal standard benzotriazole $(50 \mu \mathrm{M})$. Two volumes of ethyl acetate were added to the samples and vortexed for 10 minutes, followed by centrifugation at $10,000 \mathrm{~g}$ for 10 minutes. Samples were placed in $-80^{\circ} \mathrm{C}$ to quickly freeze the aqueous phase, and the organic layer was collected. The remaining aqueous phase was extracted a second time using the same protocol described above. The organic phase was pooled from the two extractions and evaporated under gentle heat $\left(35-40^{\circ} \mathrm{C}\right)$ on a dry heat block in the fume hood. The remaining residue was reconstituted in $100 \mu \mathrm{l}$ of the mobile phase (ultrapure water with $0.1 \%$ acetic acid) by vigorous mixing.

High-performance liquid chromatography (HPLC) system used consisted of a Waters (Milford, MA) 510 HPLC Pump, Waters 717plus Autosampler, and Waters 2487 Dual $\lambda$ Absorbance Detector controlled using Empower Pro software (Waters). The mobile phase (phase A) was ultrapure water with $0.1 \%$ acetic acid, and the organic phase (phase B) was acetonitrile with $0.1 \%$ acetic acid; all phases were degassed by vacuum filtration. Reconstituted samples $(40 \mu \mathrm{l})$ were injected onto a $\mathrm{C}_{12}$ Synergi $4 \mu \mathrm{m}$ Max-RP $80 \AA(250 \times 4.6 \mathrm{~mm})$ liquid chromatography column (Phenomenex, Torrance, $\mathrm{CA}$ ) with a guard column. The flow rate was set at $1 \mathrm{ml} / \mathrm{min}$ using the following linear gradient protocol:

Samples were monitored using the absorbance module at $\lambda=273$ $\mathrm{nm}$. Retention time ratios between $\mathrm{CAF}$ and internal standard benzotriazole were consistent between injections. For each sample, the ratio between the area under the curve (AUC) of the CAF peak $\left(\mathrm{AUC}_{\mathrm{CAF}}\right)$ and benzotriazole peak $\mathrm{AUC}\left(\mathrm{AUC}_{\mathrm{Bza}}\right)$ was calculated. A standard curve was developed using known CAF concentrations and their respective $\mathrm{AUC}_{\mathrm{CAF}}: \mathrm{AUC}_{\mathrm{Bza}}$ ratios, and unknowns were calculated using this linear regression.

Anesthesia Protocols. For the main study (cohort 1), mice were briefly anesthetized with HAL delivered in a plastic induction chamber with $2.0 \%$ HAL in medical air ( $\mathrm{v} / \mathrm{v}$ ) for $\leq 2$ minutes and transferred prone on a Peltier thermostatic platform. A rectal probe was inserted with feedback control to the platform to maintain the core body temperature of each mouse between 35 and $37^{\circ} \mathrm{C}$ to prevent fulminant hyperthermia (elevated core temperature and hypercontraction). Maintenance at $1.5 \% \mathrm{HAL}(\mathrm{v} / \mathrm{v})$ continued for up to 45 minutes delivered through a nosecone. HAL (1.5\% v/v) was used for maintenance anesthesia because it approximates one minimum alveolar concentration or the anesthetic $\mathrm{EC}_{50}$ value. In clinical practice, patients are exposed to 0.5-1.3 minimum alveolar concentration. Respiration was monitored visually and time to respiratory arrest scored with the observer blinded to treatment group. Analysis of these data failed to show sex differences, and the data were combined for analysis. Statistical comparisons of percent survival across groups was based on loss respiration using Kaplan-Meier survival analyses followed by a log-rank/Mantel-Cox test (GraphPad Prism Software, La Jolla, CA, with $P<0.05$ considered significant).

For the electrographic pilot study (cohort 2) mice were lightly preanesthetized with i.p. $10 \mathrm{mg}$ xylazine hydrochloride and $100 \mathrm{mg}$ ketamine hydrochloride for 10 minutes to accommodate placement of subcutaneous needle electrodes prior to initiating maintenance HAL anesthesia as described above. Electrographic electrodes were placed to obtain simultaneous recordings of EEG, respiratory rate, and electrocardiogram (ECG) before (baseline period) and after commencing maintenance anesthesia with $1.5 \%$ HAL though a nosecone (maintenance period). To determine the possible influences of DAN on HET mice without or with dietary CAF, a separate set of HET mice without (HET+VEH; $n=3)$ or with (HET+CAF; $n=4)$ were injected with i.p. $2.5 \mathrm{mg} / \mathrm{kg}$ DAN 20 minutes prior to commencing the placement of EEG electrodes, as described above. Data were continuously acquired for 10 minutes before initiation of maintenance anesthesia to simultaneously monitor baseline EEG, respiration, ECG, and core body temperature patterns (baseline period). Once 10 minutes of baseline data were acquired, mice were maintained with $1.5 \% \mathrm{HAL}(\mathrm{v} / \mathrm{v}$ in medical air) through a nosecone (maintenance period) while EEG, respiration, ECG, and core temperature were continuously recorded for the duration of the experiment, which lasted 


\begin{tabular}{lcc}
\hline Time $(\min )$ & $\% \mathrm{~A}$ & $\% \mathrm{~B}$ \\
\hline 0 & 100 & 0 \\
30 & 50 & 50 \\
35 & 0 & 100 \\
40 & 100 & 0 \\
55 & 100 & 0 \\
\hline
\end{tabular}

up to 60 minutes for WT groups or until heart rate became undetectable (HET groups).

Electroencephalographic Study Details. EEG, respiratory rate, and ECG were recorded simultaneously with a Nihon Kohden digital wireless EEG system (Irvine, CA) with continuous video monitoring. Electrode location and names were according to the International 10-20 system and are depicted in Supplemental Figure 1 (Klem et al., 1999) A transverse bipolar montage was selected. Recording channels were placed in the central region and included left aural to the left central $\left(\mathrm{A}_{1}-\mathrm{C}_{3}\right)$, left central to central vertex $\left(\mathrm{C}_{3}-\mathrm{Cz}\right)$, central vertex to right central $\left(\mathrm{Cz}-\mathrm{C}_{4}\right)$, and right central to right aural $\left(\mathrm{C}_{4}-\mathrm{A}_{2}\right)$. These central regions were selected because they were least affected by artifacts in the event of movement; thus, quantitative analysis was limited to this configuration (Williams et al., 2008). Two electrodes for the recording of ECG were placed subcutaneously on the left side at the level of the base and apex of the heart (Supplemental Fig. 1). Twelve consecutive 10-second epochs of recording were also selected immediately before commencing 1.5\% HAL anesthesia (defined as baseline period), and three consecutive 10-second epochs every 5 minutes thereafter until the end of the study defined as the maintenance period (45 minutes for WT mice, at cessation of a detectable heart beat for $\mathrm{MH}$ susceptible mice). Standard quantitative EEG values [power in each frequency band, total power, median frequency, spectral edge (95\%), and suppression ratio] were calculated, and additional analysis such as evaluation of paroxysmal activity was performed and statistically analyzed (Origin Pro 9; OriginLab, Northampton, MA). Paroxysmal activity included spikes (duration $<70$ millisecond), sharp waves (70 to $<200$ millisecond), and spike-and-slow waves ( $>200$ millisecond).

For both baseline and maintenance periods, epochs were visually examined using a transverse bipolar montage (Kochs et al., 1993). Each epoch was processed with software that used a fast Fourier transform analysis for calculation of peak frequency and power, plus absolute power (squared microvolts) in each frequency band (Hertz) (Kochs et al., 1993). Frequency band definition consisted of $\delta(>0$ to $<4$ $\mathrm{Hz}), \theta(4$ to $<8), \alpha$ ( 8 to $<13), \beta(13$ to $<30)$, and $\gamma(>30)$. Total power (all bands combined) was calculated from these data. Frequency (Hertz) and amplitude (microvolts) were also calculated.

Linear mixed effects models (Laird and Ware, 1982; Fitzmaurice et al., 2004) were employed to determine the difference in the baseline EEG total power and normalized EEG total reduction fraction during the HAL maintenance period among the treatment groups. For the baseline EEG total power, discrete time and treatment were used as fixed effects to investigate influences in mean EEG total power and random intercept for mouse to account for the correlation between the repeated measurements for each mouse over time. For the maintenance phase of the study, normalized EEG total reduction fraction, discrete time, treatment, and time*treatment interaction were included as fixed effects to describe the mean effects of these factors. Random intercepts for mouse and time nested within mouse were used to account for the correlations between the repeated measurements for the same mouse over time and multiple measurements from each mouse at each time, respectively. Pairwise post hoc testing was performed, and multiple comparisons for the main effects of treatment were corrected by the Tukey-Kramer (Kramer, 1956) method for unbalanced data. Due to the large number of pairwise comparisons performed for the interaction of treatment*time, the false discovery rate (FDR) (Benjamini and Hochberg, 1995) method was applied for multiple testing correction, reflecting the nature of this pilot study whose primary aim is to generate hypotheses for future larger scale studies, for which some false positive is acceptable. The FDR procedure has greater power than some more conservative methods such as the Bonferroni correction, which was also generated as a sensitivity analysis. Mixed effects models were conducted using SAS 9.4 Proc Mixed, and the FDR procedure and the Bonferroni correction were performed using Proc Multtest (SAS Institute, Cary, NC); an adjusted $P$ value $<0.05$ was considered statistically significant.

Clinical Chemistry Analysis. Blood was collected from a separate set of VEH- or CAF-exposed WT and HET mice to analyze baseline clinical chemistry in the absence of HAL anesthesia to obtain reference baselines and determine possible genotype differences to dietary CAF. Additional WT and HET mice were subjected to the maintenance HAL protocol described above, maintaining core temperature. A additional group of HET mice were subjected to the same HAL protocol, but core temperatures were permitted to rise freely to $39-40^{\circ} \mathrm{C}$ at which time they triggered a fulminant $\mathrm{MH}$ episode characterized by generalized rigor of the limbs and tail as previously reported (Yang et al., 2006; Cherednichenko et al., 2008; Feng et al., 2011; Giulivi et al., 2011; Truong and Pessah, 2019), at which time blood was collected.

For all animals, blood was collected by blind cardiac puncture using a syringe with a 25 -gauge needle; the needle was inserted below the xiphoid process of the sternum through the diaphragm with a slight bias to the right to target the apex of the heart. Mice were exsanguinated through this process, which provided up to $1 \mathrm{ml}$ of whole blood; all animals were cervically dislocated after exsanguination. Blood was stored at $4^{\circ} \mathrm{C}$ in $\mathrm{BD}$ Vacutainer tubes treated with heparin with gel separator (BD, Franklin Lakes, NJ). Plasma was separated by centrifugation at $2000 \mathrm{~g}$ for 10 minutes at $4^{\circ} \mathrm{C}$. Samples were delivered fresh on ice to the Veterinary Medicine Teaching Hospital Clinical Diagnostic Laboratory Services at UC Davis for analysis.

Blood chemistry parameters were sorted into the following categories: electrolytes (sodium, potassium, calcium, magnesium, chloride) and $\mathrm{pH}$ (anion gap, bicarbonate). Data were analyzed using a one-way ANOVA with Tukey's posttest.

Measurement of RYR1 Single-Channel Activity in Bilayer Lipid Membrane. RYR1 single channels from junctional sarcoplasmic reticulum (SR) prepared from WT animals were incorporated by inducing fusion of junctional SR vesicles with a planar bilayer lipid membrane (BLM) composed of $30 \mathrm{mg} / \mathrm{ml}$ phosphatidylethanolaminephosphatidylserine-phosphatidylcholine (5:3:2 w/w in decane; Avanti Polar Lipids, Alabaster, AL). The BLM formed across a $200 \mu \mathrm{m}$ apparatus partitioned two sides that were defined as cis (cytoplasmic) and trans (luminal) sides of the channel. Both cis and trans chambers were filled with solutions buffered by $20 \mathrm{mM}$ HEPES at pH 7.4. RyR1containing membrane vesicles were added to the cis chamber, which was defined as the cytoplasmic side. Test compounds (CAF and/or HAL) were added from freshly prepared $10 \times$ stocks to the cis chamber containing $500 \mathrm{mM} \mathrm{CsCl}$ and $2 \mu \mathrm{M}$ free $\mathrm{Ca}^{2+}$ adjusted by EGTA according to the software Bound and Determined (Brooks and Storey, 1992). The cis side served as virtual ground. The trans chamber was held at $-40 \mathrm{mV}$ and contained $50 \mathrm{mM} \mathrm{CsCl}$ and $100 \mu \mathrm{M} \mathrm{Ca}^{2+}$. Singlechannel gating activity was recorded and filtered at $1 \mathrm{kHz}$ (Low-Pass Bessel Filter 8 Pole; Warner Instruments, Hamden, CT) before being acquired through Digidata 1320A and AxoScope 10 software (Molecular Devices, Sunnyvale, CA). Analysis of single-channel open probability $\left(\mathrm{P}_{\mathrm{o}}\right)$ and mean open dwelling time constant $(\tau)$ was calculated using pClamp 9 software (Molecular Devices). All single-channel recordings were made at ambient $23-25^{\circ} \mathrm{C}$.

pClamp 9 software was used to capture and analyze single-channel gating kinetics. OriginLab 9.1 and Prism GraphPad 8 (San Diego, CA) were used for statistical analysis and plotting graphs. The detailed methods for sampling sizes and statistical analysis are described under Results and specifically indicated in each figure legend. All statistical analyses/intergroup comparisons were specified $(P \leq 0.05)$ before any data were obtained, and outcomes of all performed statistical tests are reported, irrespective of $P$ values actually obtained. 
Preparation and Culture of Primary Skeletal Myoblasts. Primary skeletal myoblasts were isolated from neonatal WT and R163C (HET) mice, as described previously in Beam and Knudson (1988) and Rando and Blau (1994). Myoblasts were grown in cell culture-treated dishes coated with calfskin collagen (Sigma-Aldrich) in Ham's F-10 medium containing 20\% (v/v) bovine growth serum (HyClone; GE Healthcare Life Sciences, Logan, UT), 2 mM L-glutamine, penicillin $\mathrm{G}$, streptomycin sulfate, and $4 \mathrm{ng} / \mathrm{ml}$ fibroblast growth factor (Peprotech, Rocky Hill, NJ) at $37^{\circ} \mathrm{C}$ in $5 \% \mathrm{CO}_{2}$ and $10 \% \mathrm{O}_{2}$. For $\mathrm{Ca}^{2+}$ imaging experiments, cells were plated onto 96 -well $\mu$ Clear plates (Corning Life Sciences, Tewksbury, MA) coated with Matrigel (Corning Life Sciences). Upon reaching $\sim 80 \%$ confluence, the cells were differentiated into myotubes over a period of 3 to 4 days in DMEM containing $5 \%(\mathrm{v} / \mathrm{v})$ heat-inactivated horse serum, $2 \mathrm{mM}$ L-glutamine, penicillin $\mathrm{G}$, and streptomycin sulfate at $37^{\circ} \mathrm{C}$ in $5 \% \mathrm{CO}_{2}$ and $10 \% \mathrm{O}_{2}$. All recordings were made at ambient $23-25^{\circ} \mathrm{C}$. Myotubes were loaded with Fluo-4 and imaged using an inverted microscope as previously described (Feng et al., 2011). Drug applications, singly or in combinations, were performed using a closed perfusion system driven by peristaltic pumps at a constant flow rate of $2.5 \mathrm{ml} / \mathrm{min}$ interspersed with 2 minutes of washout with buffer between drug applications. All HAL-containing reservoir solutions were sealed and shielded from light.

All data represent means \pm S.E. $P \leq 0.05$, comparing between genotypes at each CAF concentration (one-way ANOVA with Bonferroni's posttest, using OriginLab 9.0).

\section{Results}

Dietary CAF Significantly Shortens Time to Respiratory Arrest of HET Mice Without Influencing Basal Blood Chemistry. Mice exposed to CAF $(0.2 \mathrm{mg} / \mathrm{ml})$ through drinking water for seven or more days achieved a median plasma CAF concentration of $893 \mathrm{ng} / \mathrm{ml}(4.6 \mu \mathrm{M})$ at the time they were exposed to anesthesia and did not differ between genotypes (Fig. 1C; trough). Considering the relatively abbreviated CAF half-life in mice (Hartmann and Czok, 1980) and the nocturnal behavior of these animals, we sought to estimate the pharmacokinetic peak achieved through our dosing scheme by collecting blood at nighttime from a separate set of animals. From 10 samples collected in this manner, the peak median CAF concentration was $25.6 \mu \mathrm{M}$ (Fig. 1C; peak). The trough and peak values serve as estimators of the CAF concentration range available to deliver to systemic organs, including skeletal muscle and brain. These levels are within the target range of the median human plasma concentrations of CAF in developed countries (Smith et al., 1982; Barone and Roberts, 1996; de Leon et al., 2003; Mitchell et al., 2014).

Despite achieving the desired levels of plasma CAF concentrations in mice, $\mathrm{CAF}$ did not influence baseline blood chemistry biomarkers for electrolytes, $\mathrm{pH}$, renal, or liver function compared with the noncaffeinated group (Supplemental Table 1; first four columns). Furthermore, there were no significant genotype-specific differences in the absence or presence of dietary CAF (Supplemental Table 1; first four columns). Thus, dietary levels of CAF achieved in the present study do not significantly alter blood chemistry readings across genotypes under baseline conditions.

A separate cohort of WT and HET mice (cohort 1) were assigned to treatment groups with and without CAF exposure to test the hypothesis that dietary CAF attaining blood levels measured in human plasma exacerbates the penetrance of $R Y R 1 \mathrm{MH}$ susceptibility mutations triggered by gaseous anesthetic. In sharp contrast to basal blood biomarkers, ventilation with $1.5 \%(\mathrm{v} / \mathrm{v})$ HAL resulted in significant shortening in survival time (time to respiratory arrest) in HET mice receiving dietary CAF compared with HET mice receiving VEH (Fig. 2, inset table; $P=0.0026$ ). The median time to respiratory arrest during maintenance anesthesia for HET mice dosed with VEH was 14.5 minutes, whereas HET mice exposed to dietary CAF had a median survival time of 10.5 minutes. Although the loss of respiration was also observed with WT mice in the VEH (1 of 13 tested)- and CAF ( 3 of 16 tested)-exposed groups at 45 minutes, survival was not significantly different between WT treatment groups $(P=0.60$, Mantel-Cox).

DAN inhibits RYR1 channel activity and is currently the standard of care for MH (Ratto and Joyner, 2019; Rosen et al., 2019). As shown in Figure 2 and its inset table, DAN $(2.5 \mathrm{mg} / \mathrm{kg}$ i.p.) administered 20 minutes prior to HAL anesthesia of HET significantly prolonged median times to respiratory arrest in both VEH- and CAF-exposed HET groups: - CAF (+VEH) from 14.5 to 30 minutes $(P=0.0007)$ and $+\mathrm{CAF}$ from 10.5 to 24 minutes $(P<0.0001)$. DAN treatment also eliminated the influence of dietary CAF (+VEH+DAN vs. +CAF+DAN; $P=0.3820$ ) while reducing the steepness of the survival curves for both treatment groups such that respiratory arrest occurred over a broader span of time (Fig. 2).

Dietary CAF Does Not Alter Baseline Cortical EEG but Reduces Time to isoEEG During HAL Maintenance Period. Given that dietary CAF significantly shortens time to lethal outcome (respiratory arrest) with HAL anesthesia (Fig. 2) in the absence of fulminant hyperthermia or measurable alterations in blood chemistry, we conducted a pilot study with mice instrumented for electrographic recording (cohort 2; Supplemental Fig. S1). This approach provides an independent means to monitor central (EEG) and peripheral (respiration rate and ECG) responses to HAL in real time. Since respiratory arrest triggered by $1.5 \% \mathrm{HAL}$ anesthesia occurred in the absence of hyperthermia and muscle rigidity characteristic of a fulminant $\mathrm{MH}$ episode, we analyzed cortical EEG $_{\mathrm{TP}}$, respiratory rate, and ECG rate simultaneously to assess possible differences across genotype and treatment groups. During the initial baseline period, prior to commencing maintenance anesthesia with 1.5\% HAL, WT and HET mice failed to show significant differences in $\mathrm{EEG}_{\mathrm{TP}}$ (microvolts) whether or not they received dietary CAF (data not shown).

The electrographic protocol used during maintenance anesthesia also incorporated feedback cooling to maintain core body temperature between 35 and $37^{\circ} \mathrm{C}$, which precluded the onset of acute hyperthermia (Fig. 3A) typically associated with the fulminant MH episode in the HET mouse line (Yang et al., 2006; Feng et al., 2011). Nevertheless, HAL anesthesia proved lethal to HET mice: review of video recordings indicated the absence of muscle twitches, nor did they exhibit signs of skeletal muscle contracture or flexion of the limbs and tail at the time of respiratory and cardiac arrest (data not shown). Mice were flaccid at the time of death and remained so until rigor mortis set in $>30$ minutes postmortem. All WT mice in the cohort 2 study recovered from anesthesia regardless of CAF exposure. In contrast, HET mice sequentially lost detectable respiration and ECG with mean latencies of $14.4 \pm$ 0.8 and $24.2 \pm 5.2$ minutes, respectively (Fig. $3, \mathrm{~B}$ and C). HET mice exposed to dietary CAF had a $29 \%$ shorter time to respiratory arrest $(P=0.005)$, with cardiac arrest also showing 
A

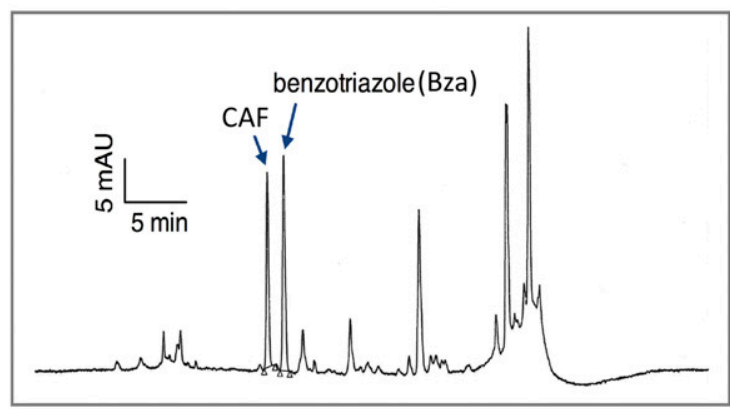

B

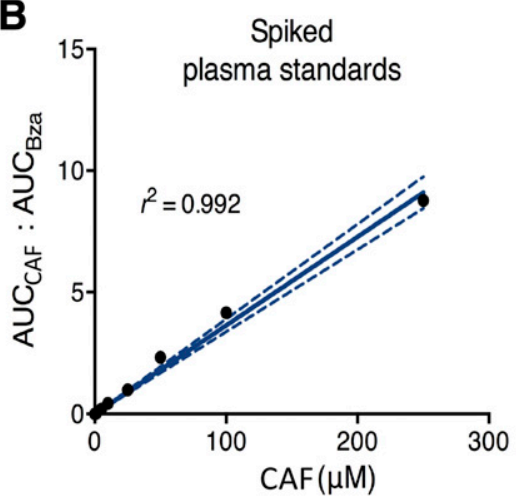

C

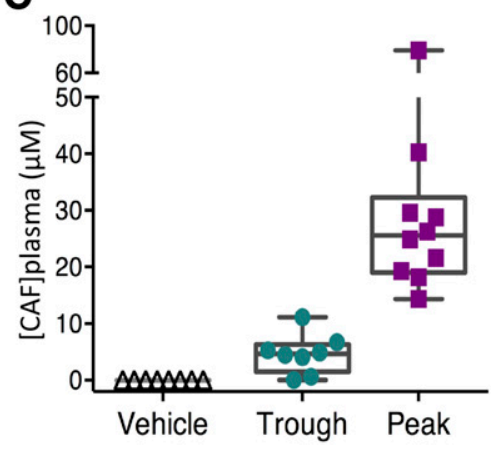

Fig. 1. Plasma CAF concentrations from dosed mice detected using HPLC. Mice were provided CAF $(0.2 \mathrm{mg} / \mathrm{ml})$ ad libitum in drinking water containing $5 \%$ sucrose, or VEH containing just $5 \%$ sucrose, for $\geq 7$ days. Blood was collected at the conclusion of each experiment. All plasma samples (standards and unknowns) were spiked with an equal concentration of the internal standard benzotriazole (Bza) prior to extraction. (A) Representative HPLC chromatogram showing the absorbance peaks corresponding to caffeine and benzotriazole at $\lambda=273$ nm. (B) Representative standard curve correlating known caffeine concentration (spiked blank plasma samples) to the $\mathrm{AUC}_{\mathrm{Caff}}$ normalized to that of the internal standard $\left(\mathrm{AUC}_{\mathrm{Bza}}\right)$. (C) Plasma caffeine concentrations determined using this method from both VEH- and CAF-treated (trough, peak) mice. Trough values were obtained using blood collected during daytime at the conclusion of in vivo experiments; peak values were obtained from blood collected immediately after euthanasia at nighttime. Box and whiskers represent first quartile, median, third quartile, and range of concentrations detected.
$29 \%$ shorter mean time although not reaching statistical significance, likely due to large variability in the measurement (Fig. 3, B and C). HET mice receiving DAN $(2.5 \mathrm{mg} / \mathrm{kg}$ i.p.) 20 minutes before initiating $\mathrm{HAL}$ anesthesia had 2.3-2.7-fold longer time to respiratory arrest $(P<0.05$; Fig. 3B) regardless of CAF treatment. DAN also prolonged the time to loss of ECG in HET mice exposed to VEH 1.6-fold $(P<0.05)$, although the differences in respective latencies did not reach significance in mice receiving dietary CAF (Fig. 3C).

Blood samples collected from a subset of cohort 2 HET mice at the time of death $(\mathrm{HET}+\mathrm{VEH})$ or at an equivalent time from (WT+VEH) showed modestly elevated plasma potassium $(128 \%)$ and magnesium (116\%), whereas anion gap and phosphorus were elevated $177 \%$ and $196 \%$, respectively, indicating moderate acidosis associated with an adverse metabolic response at the time of death compared with plasma samples collected from WT mice subjected to the same HAL protocol [Supplemental Table 1; WT+CAF+HAL vs. HET+CAF+HAL: no fulminant $\mathrm{MH}(\mathrm{FMH})$ achieved]. A separate group of mice was subjected to the same HAL anesthesia protocol with the exception that their core body temperature was not clamped within the normal physiologic range (no feedback cooling was applied); rather they were permitted to progress to fulminant hyperthermia and generalized skeletal muscle contracture as previously described (Chelu et al., 2006; Yang et al., 2006; Yuen et al., 2012). HET mice with FMH had significantly elevated plasma sodium (109\%), potassium (206\%), calcium (140\%), magnesium (136\%), and phosphorous $(290 \%)$ and an elevated anion gap (280\%) and reduced bicarbonate $(48 \%)$ compared with WT control, indicating severe acidosis and hyperkalemia at the time of death [Supplemental Table 1, $\mathrm{WT}+\mathrm{CAF}+\mathrm{HAL}$ (no FMH) vs. HET+CAF+HAL (FMH)].

The temporal change in $\mathrm{EEG}_{\mathrm{TP}}$ during the HAL maintenance period was further analyzed as the reduction fraction normalized to the baseline EGG $\mathrm{TP}_{\mathrm{TP}}$ measured for each mouse. Figure 4 summarizes the temporal patterns in EEG $_{\mathrm{TP}}$ throughout the maintenance phase. Although mice in $\mathrm{WT}+\mathrm{VEH}$ and $\mathrm{WT}+\mathrm{CAF}$ showed a modest decline in $\mathrm{EEG}_{\mathrm{TP}}$ during the

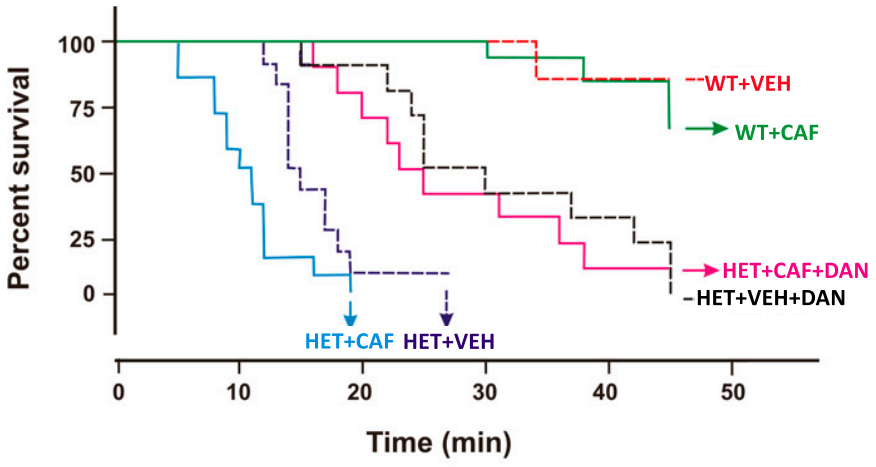

\begin{tabular}{|lc|}
\hline \multicolumn{2}{c|}{ Mantel-Cox } \\
\hline (HET+VEH) vs (HET+CAF) & $p=0.0026$ \\
(HET+VEH-DAN) vs (HET+VEH+DAN) & $p=0.0007$ \\
(HET+CAF) vs (HET+CAF+DAN) & $p<0.0001$ \\
(HET+VEH+DAN) vs (HET+CAF+DAN) & $p=0.3820$ \\
\hline
\end{tabular}

Fig. 2. CAF treatment decreases time to respiratory arrest in $\mathrm{R} 163 \mathrm{C}$ (HET) mice exposed to HAL, an effect partially rescued by DAN. WT and HET mice were dosed $\geq 7$ days with VEH or CAF to obtain blood levels shown in Figure 1. Mice (cohort 1 ) were randomly assigned to one of eight treatment groups as follows: $\mathrm{WT}+\mathrm{VEH}(n=13), \mathrm{WT}+\mathrm{CAF}(n=16), \mathrm{HET}+\mathrm{VEH}$ $(n=13), \mathrm{HET}+\mathrm{CAF}(n=14), \mathrm{HET}+\mathrm{VEH}+\mathrm{DAN}(n=11)$, and HET+CAF+DAN $(n=10)$. Mice were exposed to $1.5 \% \mathrm{HAL}$ ( $\mathrm{v} / \mathrm{v}$ in air). The survival functions (respiratory arrest) were summarized in the Kaplan-Meier survival functions for all six genotype and treatment groups up to 45 minutes. One set of HET mice received a single dose of DAN ( $2.5 \mathrm{mg} / \mathrm{kg}$ i.p.) before commencing HAL anesthesia $(\mathrm{HET}+\mathrm{VEH}+\mathrm{DAN}$ and $\mathrm{HET}+\mathrm{CAF}+\mathrm{DAN})$. Survival curves were compared using log-rank/Mantel-Cox test (inset table). 

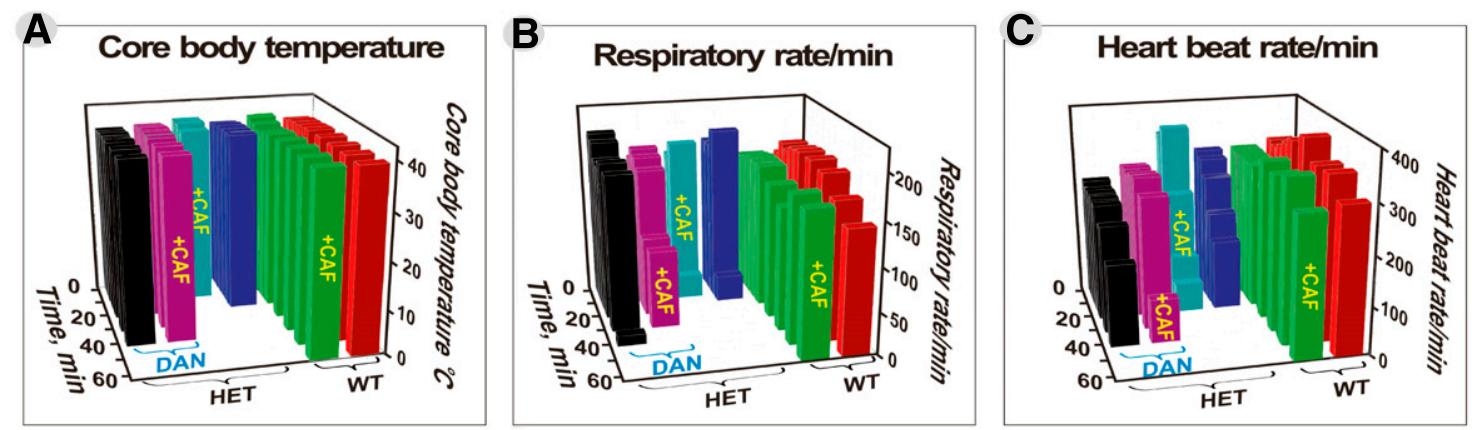

Time to Respitory Arrest, min

Time to ECG Arrest, min

\begin{tabular}{|c|c|c|c|}
\hline Genotype & CAF & DAN & $\begin{array}{c}\text { Resp. Arrest } \\
(\text { Mean+SD) } \\
\text { min }\end{array}$ \\
\hline \multirow{2}{*}{ WT } & - & - & $>60.0$ \\
\cline { 2 - 4 } & + & - & $>60.0$ \\
\hline \multirow{5}{*}{ HET } & - & - & $14.4 \pm 0.8$ \\
\cline { 2 - 4 } & + & - & $10.2 \pm 1.0$ \\
\cline { 2 - 4 } & + & + & $27.6 \pm 8.5$ \\
\cline { 2 - 4 } & - & + & $33.6 \pm 9.9$ \\
\hline
\end{tabular}

\begin{tabular}{|c|c|c|c|}
\hline Genotype & CAF & DAN & $\begin{array}{c}\text { ECG Arrest } \\
\text { (Mean } \pm \text { mD }) \\
\text { min }\end{array}$ \\
\hline \multirow{2}{*}{ WT } & - & - & $>60.0$ \\
\cline { 2 - 4 } & + & - & $>60.0$ \\
\hline \multirow{4}{*}{ HET } & - & - & $24.2 \pm 5.2$ \\
\cline { 2 - 4 } & + & - & $17.2 \pm 4.8$ \\
\cline { 2 - 4 } & + & + & $32.5 \pm 11.7$ \\
\hline \hline \multirow{2}{*}{ Genotype-Treatment } & $\boldsymbol{p}$ value \\
\hline HET+VEH vs HET+CAF & 0.164 \\
\hline \multicolumn{2}{|l|}{ HET+VEH vs HET+CAF+DAN } & 0.310 \\
\hline \multicolumn{2}{|l|}{ HET+VEH vs HET+DAN } & 0.032 \\
\hline \multicolumn{2}{|l|}{ HET+CAF vs HET+CAF+DAN } & 0.091 \\
\hline \multicolumn{2}{|l|}{ HET+CAF vs HET+DAN } & 0.008 \\
\hline \multicolumn{2}{|l|}{ HET+CAF+DAN vs HET+DAN } & 0.455 \\
\hline
\end{tabular}

Fig. 3. HET mice maintained with 1.5\% HAL anesthesia achieve respiratory and cardiac arrests despite maintenance of euthermic core body temperature: Dietary CAF significantly shortens time to adverse drug response, whereas DAN negates effects of CAF. Simultaneous recording of core body temperature (A), respiratory (B), and ECG (C) rates during maintained 1.5\% HAL anesthesia for a duration of 60 minutes was performed as described in Materials and Methods. Each genotype and respective treatment group had $n=3-4$ mice. OriginLab 9.0 was used to perform unpaired $t$ test, and the $P$ value, if $<0.05$ (in red), is regarded as significantly different.

maintenance period, neither time nor treatment was significantly different (Fig. 4A). In contrast, HET mice displayed significant progressive declines in $\mathrm{EGG}_{\mathrm{TP}}$ during the maintenance period with HAL reaching isoEEG within 35 minutes (Fig. 4B) regardless of CAF exposure. However, HET mice exposed to dietary CAF showed significantly shorter temporal decrements to isoEEG than HET mice exposed to vehicle alone (adjusted $P=0.025$; Fig. 4 , inset table). Interventions with DAN prior to commencing the maintenance period did not significantly alter the decay fraction compared with HET+VEH, and it was not influenced by dietary CAF (compare $\mathrm{HET}+\mathrm{VEH}$ vs. HET+DAN or HET+CAF+DAN; adjusted $P>$ 0.05; Fig. 4, inset table). However, DAN selectively eliminated the effects of dietary CAF exposure by delaying the fractional reduction in $\mathrm{EEG}_{\mathrm{TP}}$ [compare $\mathrm{HET}+\mathrm{CAF}+\mathrm{DAN}$ vs. $\mathrm{HET}+\mathrm{DAN}$ (adjusted $P=0.64$ ) or $\mathrm{HET}+\mathrm{CAF}$ (adjusted $P=0.0008$ )]. Noteworthy was the highly significant differences in the loss of $\mathrm{EEG}_{\mathrm{TP}}$ in $\mathrm{HET}+\mathrm{DAN}$ versus $\mathrm{HET}+\mathrm{CAF}$ treatment groups (adjusted $P<0.0001$; Fig. 4B, inset table).

Further results of the influences of time*treatment interactions revealed that, once controlled for false discovery rate, the most significant differences between HET+VEH versus HET+CAF occurred within the first 10 minutes of the maintenance phase of HAL anesthesia (Supplemental Table 2). In comparison, the influence of DAN was to prolong $\mathrm{EEG}_{\mathrm{TP}}$ throughout the recording time in animals exposed to dietary CAF (Supplemental Table 2).

VEH-treated HET mice rapidly lost detectable cortical brainwave activity, achieving isoEEG with a mean time of $12.3 \pm 1.9$ minutes. Mean time to isoEEG preceded the mean time to loss of ECG (50\% shorter time), regardless of whether mice received $\mathrm{VEH}$ or dietary $\mathrm{CAF}$ ( $-\mathrm{CAF}$ group: mean time from $12.3 \pm 1.9$ to $24.2 \pm 5.2$ minutes, $P=0.018$; and $+\mathrm{CAF}$ group: mean latency from $8.9 \pm 0.8$ to $17.2 \pm 4.8$ minutes, $P<$ 0.036 , respectively) (Table 1 ). At the time cortical EEG activity was lost (isoEEG), there was no evidence of alterations on ECG morphology such as absent $\mathrm{P}$ wave, wide QRS, or tall T (not shown), indicating that modest hyperkalemia observed at this time (Supplemental Table 1) was insufficient to affect changes in ECG.

Synergism of HAL and CAF Toward RYR1 SingleChannel Function. We next tested the hypothesis that CAF and HAL, in combination, produce synergistic effects on RYR1 channels, their putative molecular target. Functional RYR1 channels assemble as homotetramers. Tissues from HET mice would be expected to produce 

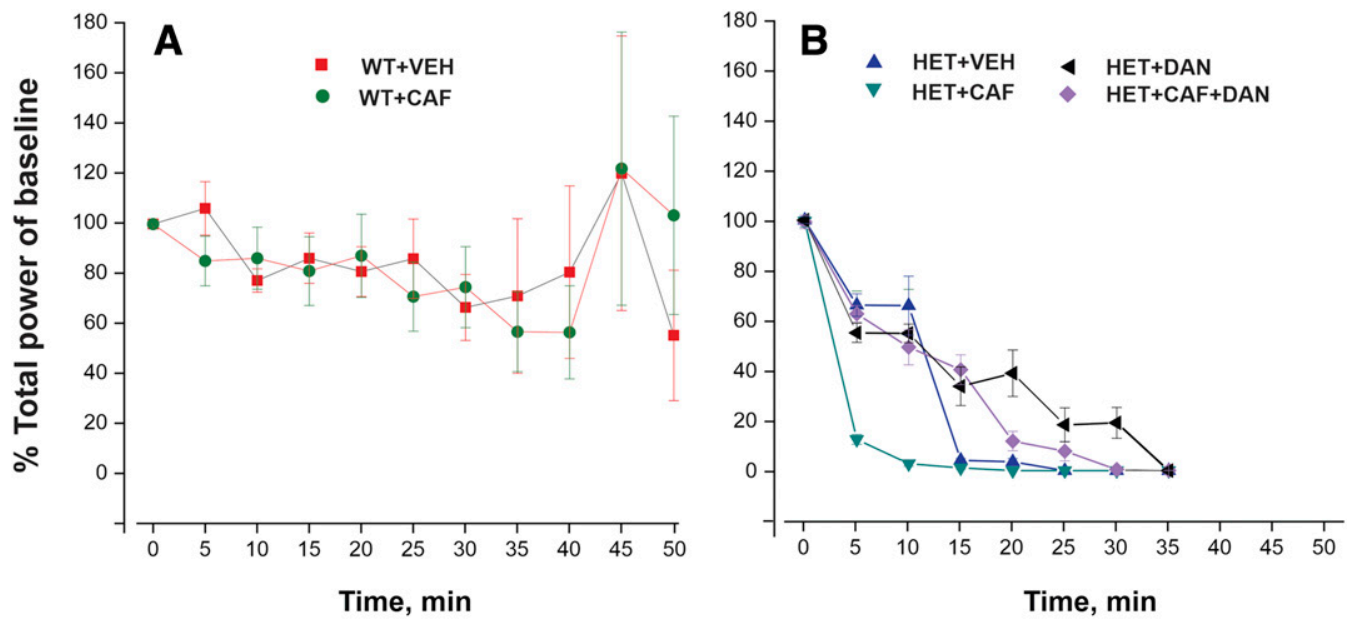

\begin{tabular}{|c|c|c|c|c|}
\hline Treatment & Treatment & Raw $\mathbf{P}(\mathbf{P r}>|\mathbf{t}|)$ & Adjustment & Adj $\mathbf{P}$ \\
\hline HET+VEH & HET+CAF+DAN & 0.42 & Tukey-Kramer & 0.85 \\
\hline HET+VEH & HET+DAN & 0.06 & Tukey-Kramer & 0.25 \\
\hline HET+VEH & HET+CAF & 0.005 & Tukey-Kramer & 0.025 \\
\hline HET+CAF+DAN & HET+DAN & 0.24 & Tukey-Kramer & 0.64 \\
\hline HET+CAF+DAN & HET+CAF & 0.0001 & Tukey-Kramer & 0.0008 \\
\hline HET+DAN & HET+CAF & $<0.0001$ & Tukey-Kramer & $<0.0001$ \\
\hline
\end{tabular}

Fig. 4. HET mice exposed to dietary CAF shortens time to isoEEG, an effect mitigated by acute DAN intervention. EEG maintenance period under 1.5\% HAL anesthesia. EEG records were binned in 5-minute intervals for a total of 50 minutes. EEG maintenance period was normalized to the mean $\mathrm{EEG}_{\mathrm{TP}}$ taken from each mouse by obtained from 9 to 12 epochs during the 2 minutes of recording during the baseline period as described in the Materials and Methods. The number of mice in each treatment group was $n=3$ to 4 (cohort 2). (A) WT and (B) HET treatment groups. Statistical analysis for the HET defined for each treatment was conducted with mixed effects models and SAS 9.4 Proc Mixed (SAS Institute). An adjusted $P$ value $<0.05$ was considered statistically significant.

WT/HET chimeric channels of all possible ratios resulting in heterogenous channel behaviors even in the presence of tightly defined cis/trans buffer solutions (Feng et al., 2011). To circumvent confounding issues that arise due to channel heterogeneity and the fact that the combination of HAL+CAF significantly synergizes responses in WT myotubes (see Fig. 7, below), we investigated whether the combination was capable of directly synergizing singlechannel kinetics isolated from WT RYR1. Accordingly, skeletal muscle junctional SR fused with BLMs to measure single-channel gating kinetics under voltage clamp. The exemplary baseline gating activity of WT RYR1 channels (two channels were incorporated in the BLM) in the presence of 2:100 $\mu \mathrm{M}$ cis:trans $\mathrm{Ca}^{2+}$ exhibited low $\mathrm{P}_{\mathrm{o}}$ that increased 21-fold upon addition of the combination HAL $(0.05 \%)$ and $\mathrm{CAF}(50 \mu \mathrm{M})$. This increase in $\mathrm{P}_{\mathrm{o}}$ resulted from decreasing mean closed time $\left(\tau_{c}\right)$ from 19.55 to 1.19 milliseconds and increasing mean open time $\left(\tau_{o}\right)$ from 0.56 to 1.86 milliseconds for level 1 (Fig. 5, traces A and B) and was coincident with the appearance of a second channel (level 2; Fig. 5, trace C). At these concentrations, CAF alone had no influence on channel $\mathrm{P}_{\mathrm{o}}$, whereas HAL alone increased $\mathrm{P}_{\mathrm{o}}$ by nearly 5 -fold (Fig. 6). However, HAL+CAF in combination increased channel $P_{o}$ an average of 18 -fold over their respective baselines in three separate experiments.

TABLE 1

HET mice exhibit significantly shorter times to isoEEG

WT and HET mice maintained with 1.5\% HAL anesthesia were instrumented to continuously record EEG and ECG as described in the Materials and Methods. Data across genotype and treatment condition were analyzed using paired $t$ test (OriginLab 9.0). Each genotype and treatment group had $n=3-4$ mice.

\begin{tabular}{lccccc}
\hline Genotype & CAF & DAN & $\begin{array}{c}\text { isoEEG } \\
\text { Mean } \pm \text { S.D., min }\end{array}$ & $\begin{array}{c}\text { ECG arrest } \\
\text { Mean } \pm \text { S.D., min }\end{array}$ & $>$ EEG vs. ECG arrest \\
$P$ value & $>60.0$ & N/A \\
WT & & - & $>60.0$ & $>60.0$ & N/A \\
& + & - & $>60.0$ & $24.2 \pm 5.2$ & 0.018 \\
HET & - & - & $12.3 \pm 1.9$ & $17.2 \pm 4.8$ & 0.036 \\
& + & - & $2.9 \pm 0.8$ & $32.5 \pm 11.7$ & 0.041 \\
& + & + & $29.8 \pm 8.8$ & $38.5 \pm 5.7$ & 0.042 \\
\hline
\end{tabular}

N/A, not applicable. 
HAL and CAF Synergize RYR1-Mediated Intracellular $\mathbf{C a}^{2+}$ Release. To further verify the hypothesis that synergism between CAF and HAL observed in vivo and in single-channel measurements, we performed single-cell $\mathrm{Ca}^{2+}$ imaging experiments with myotubes cultured from adult HET and WT mice, an established model to investigate $\mathrm{MH}$ susceptibility. Despite the fact that HET myotubes had only $40 \%$ of the releasable SR $\mathrm{Ca}^{2+}$ stores compared with WT, demonstrated by the smaller $\mathrm{Ca}^{2+}$ transient amplitude produced by $20 \mathrm{mM} \mathrm{CAF} \mathrm{(Fig.} \mathrm{7,} \mathrm{A} \mathrm{and} \mathrm{B),} \mathrm{HET} \mathrm{cells} \mathrm{were} \mathrm{more}$ sensitive to HAL ( $0.05 \% \mathrm{v} / \mathrm{v})$ (Fig. 7, A and C). Importantly, the combination of HAL and CAF produced a greatly synergized response in both genotypes compared with either drug alone (Fig. 7), but the degree of synergism was significantly greater in HET than WT with CAF $\leq 0.25 \mathrm{mM}$ due to a left shift in the concentration-effect curve by up to one order of magnitude (Fig. 7, A and C). Despite the diminished SR $\mathrm{Ca}^{2+}$ content in HET myotubes, their sensitivity to $\mathrm{HAL}+\mathrm{CAF}$ was significantly greater when normalized to the release elicited by $20 \mathrm{mM}$ caffeine, although this distinction converged at higher CAF concentrations $\geq 0.5 \mathrm{mM}$ (Fig. 7C).

\section{Discussion}

A seminal finding in the present study identifies a common dietary factor, CAF intake, synergizes adverse outcomes during maintenance anesthesia with a halogenated volatile general anesthetic, exemplified by HAL in our study, in a mouse model (R163C-RYR1; HET) of human MH susceptibility. A second new finding identifies a dominant central influence of CAF and HAL, singly or in combination, that precedes the canonical peripheral manifestation of fulminant $\mathrm{MH}$ when core body temperature is clamped within the physiologic range. The synergistic actions of $\mathrm{CAF}+\mathrm{HAL}$ exposures in HET mice elicits an ADR in vivo at blood CAF concentrations (range of 5-30 $\mu \mathrm{M}$ ) well below those needed to trigger SR $\mathrm{Ca}^{2+}$ release from WT or HET skeletal myotubes $(>100 \mu \mathrm{M})$. Measurements of RYR1 channels isolated from WT provide evidence of significant synergism of the modest influence of $0.05 \% \mathrm{HAL}(20 \mu \mathrm{M})$, with $\mathrm{CAF}(50 \mu \mathrm{M})$ enhancing RYR1 open probability nearly 30 -fold. The synergistic effects of CAF+HAL can be demonstrated in WT and HET myotubes, although it is clear that the synergistic actions are greatly amplified in the HET genotype.

Direct muscle effects alone cannot fully explain our current findings with the combination of CAF and/or HAL in vivo. Exposure of HET mice to dietary CAF that produces median plasma concentrations commensurate with those measured in human populations (Smith et al., 1982; Barone and Roberts, 1996; de Leon et al., 2003; Mitchell et al., 2014) significantly shortens the time to achieve isoEEG as well as respiratory and cardiac (ECG) arrest in HET mice. Interestingly, HET mice do not differ from WT in their baseline EEG tries, regardless of whether they were exposed to dietary CAF. These results suggest that HET mice do not differ in cortical electrical activity from WT mice during baseline recording

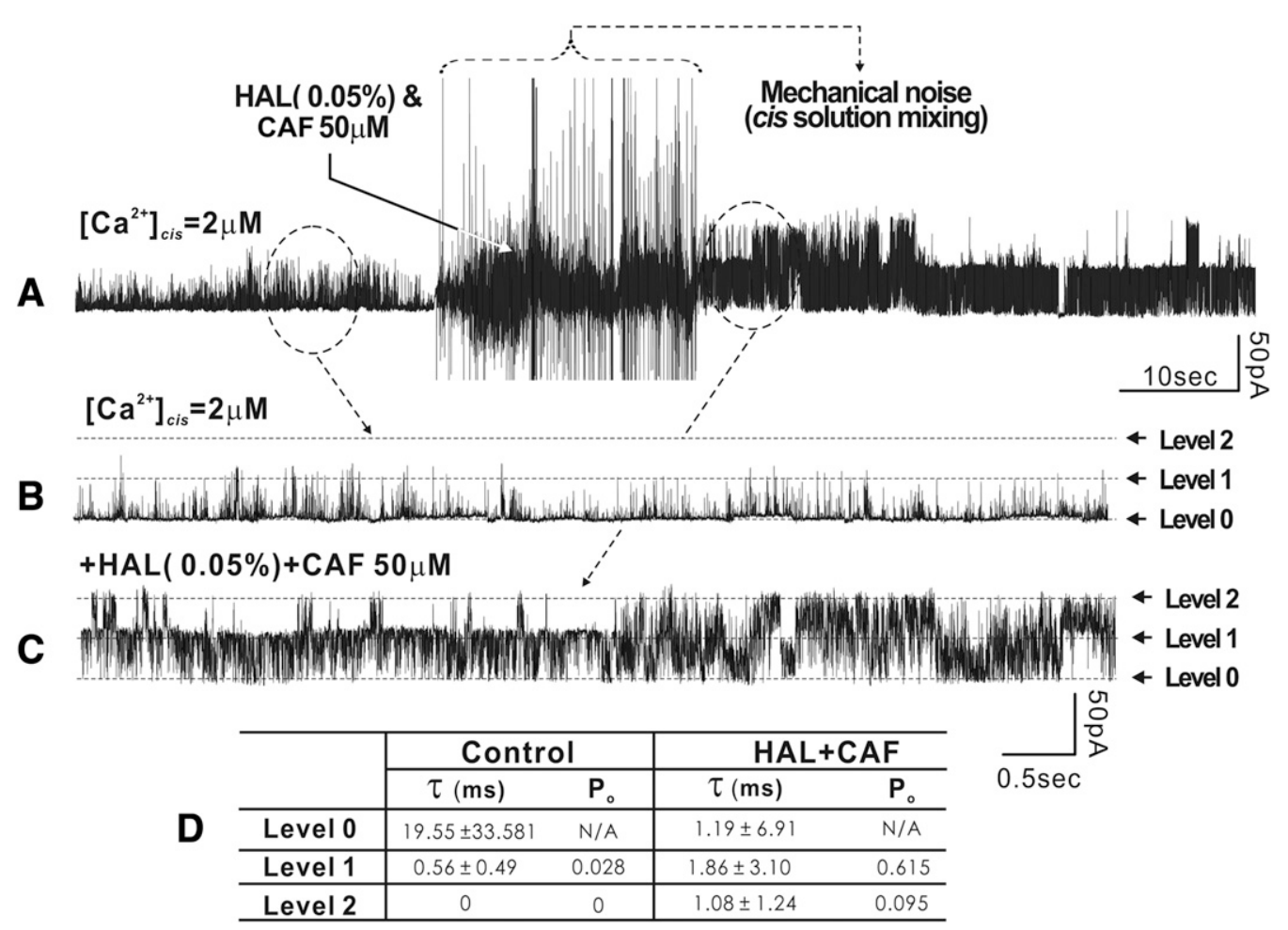

Fig. 5. Combination of CAF $(50 \mu \mathrm{M})$ and HAL $(0.05 \%)$ synergistically enhance WT RYR1 channel gating activity. (A) Exemplary gating activity of WT RYR1 channels when measured in the presence of 2 and $100 \mu \mathrm{M}$ cytoplasmic (cis) and luminal (trans) free $\mathrm{Ca}^{2+}$ side of the bilayer chamber before and after exposure to the combination of $0.05 \%$ ( $/ / \mathrm{v}$ in buffer) HAL and $50 \mu \mathrm{M} \mathrm{CAF}$. $\mathrm{Cs}^{+}$is the current carrier (see Materials and Methods). (A) shows a representative trace of an entire recording. (B and $\mathrm{C}$ ) are expanded 7 -second segments taken from trace $\mathrm{A}$ indicated by the dashed lines showing finer details of channel gating behavior before and after addition of HAL and CAF. Horizonal arrows and corresponding dashed lines to the right of traces B and $\mathrm{C}$ indicate current amplitude of the channels in the closed state (level 0), one channel in full conductance (level 1), and a second channel in full conductance (level 2). (D) summarizes the gating kinetic parameters, mean dwelling time $(\tau, \mathrm{ms})$, and $\mathrm{P}_{\mathrm{o}}$ of each of the gating level $(0,1$ and 2$)$. Data are representative of $n=3$ independent channel fusions. 

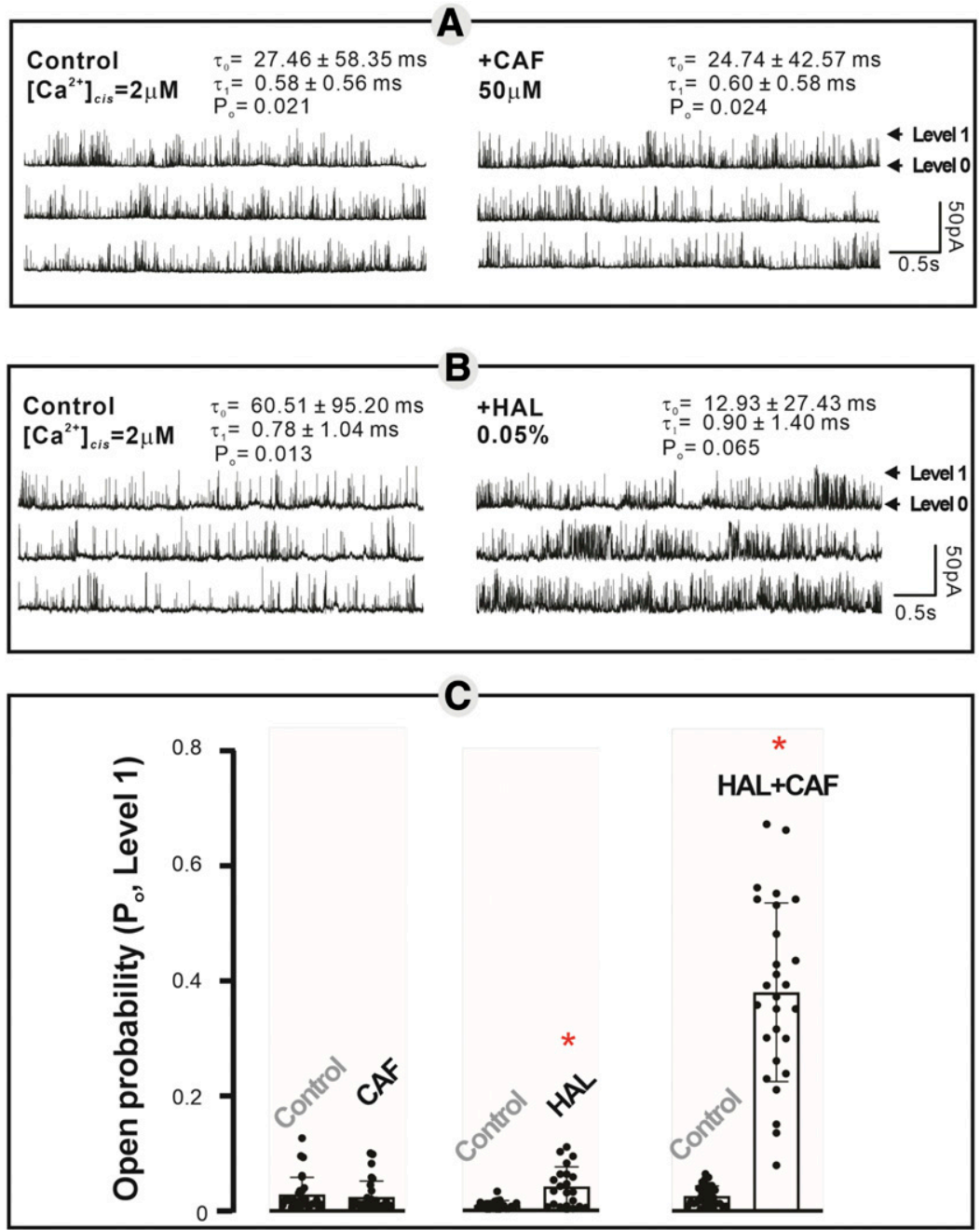

Fig. 6. Influence of $50 \mu \mathrm{M} \mathrm{CAF}, 0.05 \% \mathrm{HAL}$, or $\mathrm{CAF}+\mathrm{HAL}$ on RYR1 single-channel gating activity. $\mathrm{Cs}^{+}$currents were measured in the presence of $2 \mu \mathrm{M}$ free $\mathrm{Ca}^{2+}$ in cis and 100 $\mu \mathrm{M}$ trans. The gating of a RYR1 channel was recorded for 1 minute before being exposed to $50 \mu \mathrm{M}$ CAF (A); representative channel from $n=3$ experiments. (B) shows a representative response to addition of $0.05 \% \mathrm{HAL}(n=2$ experiments). The gating parameters of the channel, $\mathrm{P}_{\mathrm{o}}$ and the mean dwelling time at closed - level $0\left(\tau_{0}\right)$ and open state - level $1\left(\tau_{1}\right)$ are denoted by the horizontal arrows to the right of each current trace. (C) summarizes of RYR1 channel open probability for level $1\left(\mathrm{P}_{\mathrm{o}}\right)$ before and after addition of $50 \mu \mathrm{M} \mathrm{CAF}, 0.05 \%$ HAL or their combination (HAL+CAF). $\mathrm{P}_{\mathrm{o}}$ values were acquired from 10 epochs, 3 seconds per bin of each BLM measurement before and after the addition of test compound(s), allowing 20-30 seconds of mixing using a micromagnet stirring device. (C) shows $P_{o}$ values (means \pm S.D.) from RYR1 channels gating at level 1 before (control) and after exposure to $\operatorname{HAL}(n=2), \operatorname{CAF}(n=$ $3)$, or HAL+CAF mixture $(n=3)$. Statistical analysis of unpaired $t$ test was made with software GraphPad (Prism). $* P<0.05$. under the experimental conditions used in the present study. The lack of differences in baseline EEG $_{\mathrm{TP}}$ measured in HET mice during the baseline period, regardless of treatment, also extended to the EEG spectra (data not shown). Although the electrographic study (cohort 2) was powered based on the large effect size observed with of dietary CAF on time to respiratory arrest in HET mice (cohort 1), it should be viewed in light of its pilot design for generating hypotheses regarding the central influences of CAF in synergizing general volatile anesthetics and possible other triggering agents in $\mathrm{MH}$ susceptible individuals. Nevertheless, a recently published study of HET mice provided a detailed comparison of whole-body energetics and voluntary activity in HET and WT mice (Rutkowsky et al., 2020). No genotype differences were apparent in voluntary movement measured in a calorimetry chamber or decreased 24-hour energy expenditure, especially during the dark cycle when mice are most active (Rutkowsky et al., 2020). This study provides additional evidence that HET mice in their home cage environment do not differ in arousal, as measured by baseline $\mathrm{EEG}_{\mathrm{TP}}$, compared with WT mice.

Only during maintenance anesthesia with $\mathrm{HAL}$ did $\mathrm{EEG}_{\mathrm{TP}}$ decline in a genotype-, CAF treatment-, and treatment*timedependent manner. Administration of $\mathrm{HAL}$ anesthesia to HET mice resulted in the loss of EEG activity before detectable alterations in ECG patterns, regardless of whether the animals received CAF. Under the conditions used that maintain core temperature, blood drawn at the time of death (loss of detectable ECG) indicates only mild to moderate hyperkalemia and acidosis in euthermic HET mice compared with HET mice that are permitted to proceed to a fulminant $\mathrm{MH}$ episode. Collectively, these data indicate that central nervous system mechanisms contribute to susceptibility of HET mice to lethal consequences of HAL anesthesia, even in the absence of dietary $\mathrm{CAF}$, and that CAF greatly synergizes the effects of this anesthetic. The observation that DAN delays the time to isoEEG and respiratory and cardiac arrest in a time-dependent manner further suggests that the synergistic actions of dietary CAF and HAL in HET mice may be mediated through a common mechanism involving RYRs. This interpretation is supported by results obtained from myotube and single RYR1 channel experiments.

The central effects of dietary CAF are well documented and primarily mediated by its potent antagonism of adenosine receptors, causing increased excitatory neurotransmitter release that lower neuronal activation threshold (Phillis et al., 1979; Nehlig et al., 1992; Keane et al., 2007; Keane and James, 2008). Adenosine A2A receptors are found in brain areas rich in dopamine D2 receptors such as the basal ganglia, and changes induced by CAF within the basal ganglia would very likely exert a downstream effect on the motor cortex 


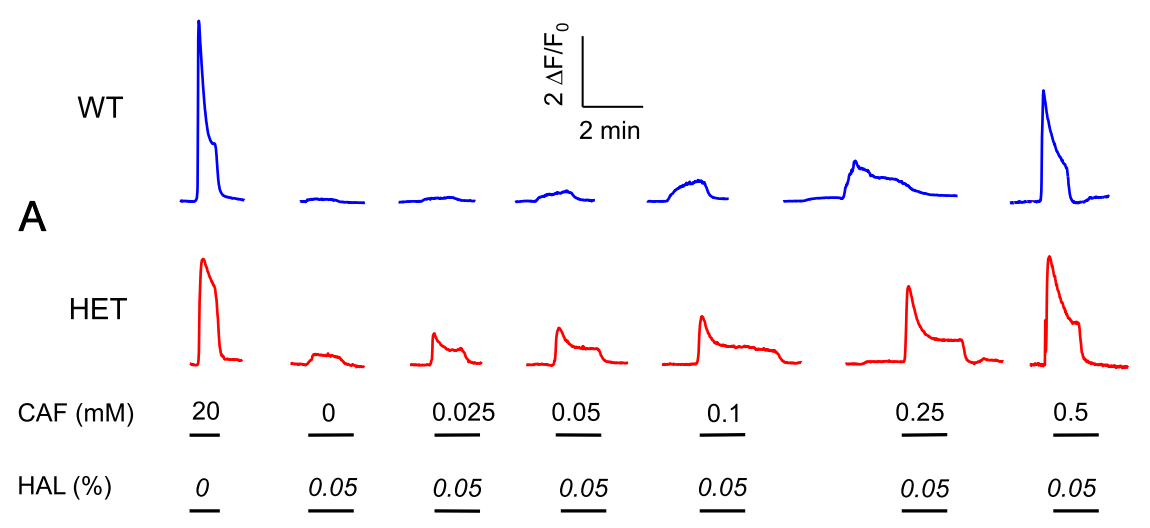

B
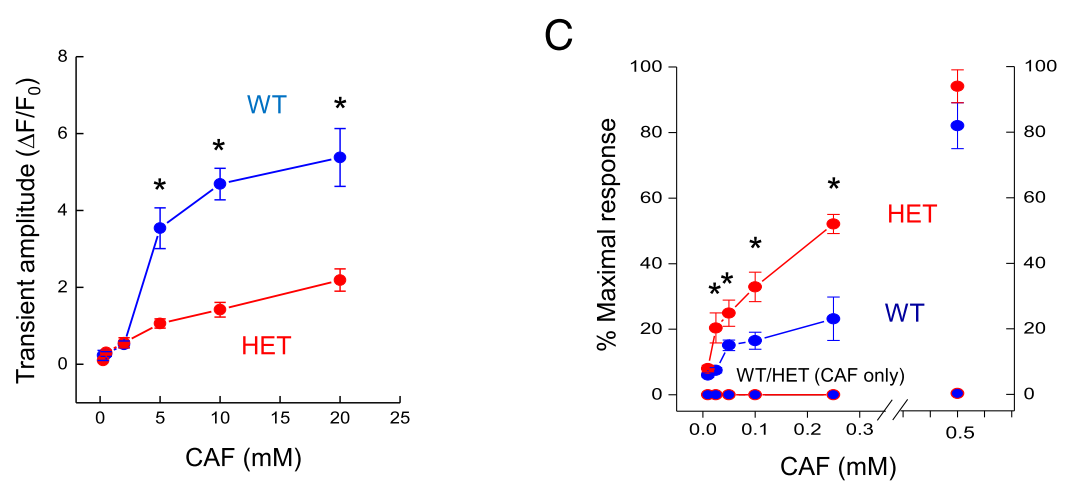

Fig. 7. Synergism between $\mathrm{CAF}$ and $\mathrm{HAL}$ enhances SR $\mathrm{Ca}^{2+}$ release in WT and HET skeletal myotubes. (A) Representative traces showing cytoplasmic $\mathrm{Ca}^{2+}$ responses recorded from WT and HET myotubes loaded with Fluo-4 exposed to the combinations CAF and HAL as indicated. Both genotypes were first exposed to a brief perfusion of CAF $20 \mathrm{mM}$ to assess the filling state of the SR store followed by a washout. Once cytoplasmic $\mathrm{Ca}^{2+}$ concentration recovered to original baseline (not shown), myotubes were exposed to a brief perfusion of HAL $(0.05 \% \mathrm{v} / \mathrm{v}$ in buffer) and allowed to recover. Subsequent exposure by perfusion with 0.025-0.5 mM CAF in the presence of HAL (kept constant at $0.05 \%$ throughout) was sequentially tested with intervening washout to recover baseline (not shown). (B) Concentration-effect response relationship of WT ( $n=12$ to 13 ) and HET ( $n=8$ to 9) myotubes to brief exposure to CAF alone $(0.25-20 \mathrm{mM})$, indicating that HET myotubes have chronically depleted CAF-sensitive SR $\mathrm{Ca}^{2+}$ stores compared with WT. (C) Data summarizing responses of WT $(n=14)$ and HET $(n=14)$ myotubes to low concentrations of CAF $(0-0.5$ $\mathrm{mM})$ in the absence or presence of constant HAL $(0.05 \% \mathrm{v} / \mathrm{v}) \cdot \mathrm{Ca}^{2+}$ transient amplitude is expressed as a percent of maximal response elicited by $20 \mathrm{mM}$ CAF. CAF alone had no effect up to 0.5 $\mathrm{mM}$. All data represent means \pm S.E. $* P \leq 0.05$, comparing between genotypes at each $\mathrm{CAF}$ concentration (one-way ANOVA with Bonferroni's post-hoc test, using OriginLab 9.0).
(Ferre et al., 1997; Fisone et al., 2004). However, CAF also antagonizes adenosine A2A receptors directly within the motor cortex by inhibiting the release of GABA, thus reducing GABAergic inhibitory transmission in the motor cortex (Cerqueira et al., 2006). Expression of RYR1 mRNA within brain regions, including cortical motor regions, has been documented, although less abundantly than RYR2 (Furuichi et al., 1994; Giannini and Sorrentino, 1995; Mori et al., 2000), although data from immunolabeling and western blot studies for RYR1 protein are more limited (Hertle and Yeckel, 2007; Feng et al., 2017), possibly due to antibody cross-reactivity. Behavioral studies using MH susceptible mice arguably provide stronger evidence for a functional role of RYR1 in the mammalian nervous system (Wayman et al., 2012; Keil et al., 2019).

There are a few studies in $\mathrm{MH}$ susceptible pigs that suggest alterations in cerebral cortical activity measured by EEG recording during the onset of the fulminant $\mathrm{MH}$ crisis in pigs (R615C-RYR1) (Artru and Gronert, 1980; Kochs et al., 1990a,b) and horses (R2454G-RYR1) (Aleman et al., 2005). Results from two studies with MH susceptible pigs showed significant depression of EEG activity preceding the onset of cardiovascular and metabolic changes during induction of halothane-triggered fulminant MH (Kochs et al., 1990a,b). One of these studies documented the temporal decrease in total power concomitant with a shift to lower frequencies (delta-theta activity) in the EEG of MH susceptible pigs maintained with $1 \%$ halothane, and these alternations preceded the development of fulminant MH (Kochs et al., 1990a).

Moreover, altered EEG patterns in MH susceptible pigs were not the result of hypotension, hypoxia, or hypercapnia, leading the authors to speculate that changes in brain wave activity were due to either systemic factors unrelated to the acute $\mathrm{MH}$ crisis or involvement of the central nervous system as a primary target in the pathophysiology of the fulminant MH syndrome (Kochs et al., 1990). In another study, EEG alterations during halothane anesthesia were interpreted as secondary to heat-induced central nervous system injury resulting from the fulminant $\mathrm{MH}$ episode (Forrest et al., 2015), a variable tightly controlled in the present study.

The question arises as to why CAF+HAL act synergistically on RYR1 channels isolated from WT tissue while producing no ADRs in WT mice exposed to HAL up to 60 minutes. Excitation-contraction coupling in skeletal muscle requires precise physical interactions between voltage-gated $\mathrm{Ca}^{2+}$ channels $\left(\mathrm{CaV}_{1.1} \mathrm{~s}\right)$ in the T-tubule and RYR1 residing in the terminal cisternae of SR (Franzini-Armstrong, 2018). Their interactions engage bidirectional signaling, both orthograde activation of RYR 1 and retrograde activation of $\mathrm{CaV}_{1.1}$ current (Nakai et al., 1996). There is strong evidence for reciprocal negative regulation of the two channels, especially orthograde suppression of RYR1 channel activity by $\mathrm{CaV}_{1.1}$, that physiologically both dampen resting $\mathrm{Ca}^{2+}$ in the myoplasm by controlling RYR1-mediated $\mathrm{Ca}^{2+}$ leak and control $\mathrm{Ca}^{2+}$ release properties during excitation-contraction coupling (Pessah et al., 1997; Bannister et al., 2009; Eltit et al., 2012). $\mathrm{MH}$ mutations weaken several aspects of $\mathrm{CaV}_{1.1}-\mathrm{RYR} 1$ negative regulation increasing RYR1 leak responsible for the chronically elevated resting $\mathrm{Ca}^{2+}$ observed in the affected myoplasm and depleted $\mathrm{SR} \mathrm{Ca}^{2+}$ stores (Yang et al., 2006; Bannister et al., 2010; Esteve et al., 2010; Eltit et al., 2012) and explain the inherently high open probabilities of RYR1 channels isolated from R163C-RYR1 (HET mouse used in the present study) and T4826I-RYR1 HET and homozygous MH susceptible 
mouse muscle, which lack $\mathrm{CaV}_{1.1}$ and negative regulation (Feng et al., 2011; Barrientos et al., 2012). MH mutations also alter excitation-coupled $\mathrm{Ca}^{2+}$ entry mediated by $\mathrm{CaV}_{1.1}$ (Yang et al., 2006; Cherednichenko et al., 2008; Bannister et al., 2010). Based on the present findings we posit that triadic complexes that possess RYR1 mutations conferring $\mathrm{MH}$ susceptibility are more sensitive to pharmacologic dysregulation by HAL and related triggering anesthetics and that dietary levels of CAF greatly synergize these disruptive influences as clearly demonstrated in vitro here. These results may provide a mechanistic framework for understanding a recent report that CAF markedly augments neurotoxicity of isoflurane in the fetal macaque brain and may have more general impacts on susceptible life stages(Noguchi et al., 2018).

Our study provides the first evidence of pharmacological synergism between a general volatile anesthetic and dietary CAF in a mouse model of MH susceptibility. The study also demonstrates early central nervous system involvement mediating adverse outcomes to dietary CAF during maintenance anesthesia with an exemplary triggering agent HAL. Dietary CAF is a modifiable lifestyle factor that may mitigate risks associated with MH-causing mutations in RYR1.

\section{Acknowledgments}

We acknowledge the guidance of Professor Alan Buckpitt in establishing the HPLC method for quantifying plasma CAF levels.

\section{Authorship Contributions}

Project conception: Pessah.

Participated in research design: Aleman, Zhang, Feng, Lopez, Cherednichenko, Pessah.

Conducted experiments: Aleman, Zhang, Feng, Lopez, Dong, Cherednichenko.

Performed data analysis: Aleman, Zhang, Feng, Qi, Lopez, Crowe, Cherednichenko, Pessah.

Wrote or contributed to the writing of the manuscript: Aleman, Zhang, Feng, Qi, Crowe, Lopez, Cherednichenko, Pessah.

\section{References}

Adeokun AM, West SP, Ellis FR, Halsall PJ, Hopkins PM, Foroughmand AM, Iles DE, Robinson RL, Stewart AD, and Curran JL (1997) The G1021A substitution in the RYR1 gene does not cosegregate with malignant hyperthermia susceptibility in a British pedigree. Am J Hum Genet 60:833-841.

Aleman M, Brosnan RJ, Williams DC, LeCouteur RA, Imai A, Tharp BR, and Steffey EP (2005) Malignant hyperthermia in a horse anesthetized with halothane. $J$ Vet Intern Med 19:363-366.

Aleman M, Riehl J, Aldridge BM, Lecouteur RA, Stott JL, and Pessah IN (2004) Association of a mutation in the ryanodine receptor 1 gene with equine malignant hyperthermia. Muscle Nerve 30:356-365.

Artru AA and Gronert GA (1980) Cerebral metabolism during porcine malignant hyperthermia. Anesthesiology 53:121-126.

Bannister RA, Estève E, Eltit JM, Pessah IN, Allen PD, López JR, and Beam KG (2010) A malignant hyperthermia-inducing mutation in RYR1 (R163C): consequent alterations in the functional properties of DHPR channels. J Gen Physiol 135: 629-640.

Bannister RA, Pessah IN, and Beam KG (2009) The skeletal L-type Ca(2+) current is a major contributor to excitation-coupled $\mathrm{Ca}(2+)$ entry. J Gen Physiol 133:79-91.

Barone JJ and Roberts HR (1996) Caffeine consumption. Food Chem Toxicol 34: 119-129.

Barrientos GC, Feng W, Truong K, Matthaei KI, Yang T, Allen PD, Lopez JR, and Pessah IN (2012) Gene dose influences cellular and calcium channel dysregulation in heterozygous and homozygous T4826I-RYR1 malignant hyperthermiasusceptible muscle. J Biol Chem 287:2863-2876.

Beam KG and Knudson CM (1988) Calcium currents in embryonic and neonatal mammalian skeletal muscle. J Gen Physiol 91:781-798.

Benjamini Y and Hochberg Y (1995) Controlling the false discovery rate: a practical and powerful approach to multiple testing. J R Stat Soc B 57:289-300.

Brandom BW, Bina S, Wong CA, Wallace T, Visoiu M, Isackson PJ, Vladutiu GD, Sambuughin N, and Muldoon SM (2013) Ryanodine receptor type 1 gene variants in the malignant hyperthermia-susceptible population of the United States. Anesth Analg 116:1078-1086.

Brooks SP and Storey KB (1992) Bound and determined: a computer program for making buffers of defined ion concentrations. Anal Biochem 201:119-126.
Cerqueira V, de Mendonça A, Minez A, Dias AR, and de Carvalho M (2006) Does caffeine modify corticomotor excitability? Neurophysiol Clin 36:219-226.

Chelu MG, Goonasekera SA, Durham WJ, Tang W, Lueck JD, Riehl J, Pessah IN, Zhang P, Bhattacharjee MB, Dirksen RT, et al. (2006) Heat- and anesthesiainduced malignant hyperthermia in an RyR1 knock-in mouse. FASEB $J$ 20: $329-330$.

Cherednichenko G, Ward CW, Feng W, Cabrales E, Michaelson L, Samso M, López JR, Allen PD, and Pessah IN (2008) Enhanced excitation-coupled calcium entry in myotubes expressing malignant hyperthermia mutation $\mathrm{R} 163 \mathrm{C}$ is attenuated by dantrolene. Mol Pharmacol 73:1203-1212.

Cornelis MC, El-Sohemy A, Kabagambe EK, and Campos H (2006) Coffee, CYP1A2 genotype, and risk of myocardial infarction. JAMA 295:1135-1141.

de Leon J, Diaz FJ, Rogers T, Browne D, Dinsmore L, Ghosheh OH, Dwoskin LP, and Crooks PA (2003) A pilot study of plasma caffeine concentrations in a US sample of smoker and nonsmoker volunteers. Prog Neuropsychopharmacol Biol Psychiatry 27:165-171.

Ding M, Bhupathiraju SN, Satija A, van Dam RM, and Hu FB (2014) Long-term coffee consumption and risk of cardiovascular disease: a systematic review and a dose-response meta-analysis of prospective cohort studies. Circulation 129: 643-659.

Eltit JM, Bannister RA, Moua O, Altamirano F, Hopkins PM, Pessah IN, Molinski TF, López JR, Beam KG, and Allen PD (2012) Malignant hyperthermia susceptibility arising from altered resting coupling between the skeletal muscle L-type $\mathrm{Ca} 2+$ channel and the type 1 ryanodine receptor. Proc Natl Acad Sci USA 109: $7923-7928$

Estève E, Eltit JM, Bannister RA, Liu K, Pessah IN, Beam KG, Allen PD, and López JR (2010) A malignant hyperthermia-inducing mutation in RYR1 (R163C): alterations in $\mathrm{Ca} 2+$ entry, release, and retrograde signaling to the DHPR. J Gen Physiol 135:619-628.

Feng W, Barrientos GC, Cherednichenko G, Yang T, Padilla IT, Truong K, Allen PD, Lopez JR, and Pessah IN (2011) Functional and biochemical properties of ryanodine receptor type 1 channels from heterozygous R163C malignant hyperthermiasusceptible mice. Mol Pharmacol 79:420-431.

Feng W, Zheng J, Robin G, Dong Y, Ichikawa M, Inoue Y, Mori T, Nakano T, and Pessah IN (2017) Enantioselectivity of 2,2',3,5',6-pentachlorobiphenyl (pcb 95) atropisomers toward ryanodine receptors (RyRs) and their influences on hippocampal neuronal networks. Environ Sci Technol 51:14406-14416.

Ferré S, Fredholm BB, Morelli M, Popoli P, and Fuxe K (1997) Adenosine-dopamine receptor-receptor interactions as an integrative mechanism in the basal ganglia. Trends Neurosci 20:482-487.

Findley AS, Richards AL, Petrini C, Alazizi A, Doman E, Shanku AG, Davis GO, Hauff N, Sorokin Y, Wen X, et al. (2019) Interpreting coronary artery disease risk through gene-environment interactions in gene regulation. Genetics 213:651-663.

Fisone G, Borgkvist A, and Usiello A (2004) Caffeine as a psychomotor stimulant: mechanism of action. Cell Mol Life Sci 61:857-872.

Fitzmaurice GM, Laird NM, and Ware JH (2004) Applied Longitudinal Analysis pp 326-328, John Wiley \& Sons, Hoboken, NJ.

Forrest KM, Foulds N, Millar JS, Sutherland PD, Pappachan VJ, Holden S, Mein R, Hopkins PM, and Jungbluth H (2015) RYR1-related malignant hyperthermia with marked cerebellar involvement - a paradigm of heat-induced CNS injury? Neuromuscul Disord 25:138-140.

Franzini-Armstrong C (2018) The relationship between form and function throughout the history of excitation-contraction coupling. J Gen Physiol 150:189-210.

Fujii J, Otsu K, Zorzato F, de Leon S, Khanna VK, Weiler JE, O'Brien PJ, and MacLennan DH (1991) Identification of a mutation in porcine ryanodine receptor associated with malignant hyperthermia. Science 253:448-451.

Furuichi T, Furutama D, Hakamata Y, Nakai J, Takeshima H, and Mikoshiba K (1994) Multiple types of ryanodine receptor/Ca2+ release channels are differentially expressed in rabbit brain. $J$ Neurosci 14:4794-4805.

Giannini G and Sorrentino V (1995) Molecular structure and tissue distribution of ryanodine receptors calcium channels. Med Res Rev 15:313-323.

Gillies RL, Bjorksten AR, Davis M, and Du Sart D (2008) Identification of genetic mutations in Australian malignant hyperthermia families using sequencing of RYR1 hotspots. Anaesth Intensive Care 36:391-403.

Gillies RL, Bjorksten AR, Du Sart D, and Hockey BM (2015) Analysis of the entire ryanodine receptor type 1 and alpha 1 subunit of the dihydropyridine receptor (CACNA1S) coding regions for variants associated with malignant hyperthermia in Australian families. Anaesth Intensive Care 43:157-166.

Giulivi C, Ross-Inta C, Omanska-Klusek A, Napoli E, Sakaguchi D, Barrientos G, Allen PD, and Pessah IN (2011) Basal bioenergetic abnormalities in skeletal muscle from ryanodine receptor malignant hyperthermia-susceptible R163C knock-in mice. J Biol Chem 286:99-113.

Hartmann M and Czok G (1980) [Pharmacokinetics of caffeine in mice and its modification by ethanol]. Z Ernahrungswiss 19:215-227.

Hertle DN and Yeckel MF (2007) Distribution of inositol-1,4,5-trisphosphate receptor isotypes and ryanodine receptor isotypes during maturation of the rat hippocampus. Neuroscience 150:625-638.

Hopkins PM, Rüffert H, Snoeck MM, Girard T, Glahn KP, Ellis FR, Müller CR, and Urwyler A; European Malignant Hyperthermia Group (2015) European Malignant Hyperthermia Group guidelines for investigation of malignant hyperthermia susceptibility. Br J Anaesth 115:531-539.

Ibarra Moreno CA, Hu S, Kraeva N, Schuster F, Johannsen S, Rueffert H, Klingler W, Heytens L, and Riazi S (2019) An assessment of penetrance and clinical expression of malignant hyperthermia in individuals carrying diagnostic ryanodine receptor 1 gene mutations. Anesthesiology 131:983-991.

Jungbluth H, Treves S, Zorzato F, Sarkozy A, Ochala J, Sewry C, Phadke R, Gautel M, and Muntoni F (2018) Congenital myopathies: disorders of excitationcontraction coupling and muscle contraction. Nat Rev Neurol 14:151-167.

Keane MA and James JE (2008) Effects of dietary caffeine on EEG, performance and mood when rested and sleep restricted. Hum Psychopharmacol 23:669-680. 
Keane MA, James JE, and Hogan MJ (2007) Effects of dietary caffeine on topographic EEG after controlling for withdrawal and withdrawal reversal. Neuropsychobiology 56:197-207.

Keil KP, Sethi S, Wilson MD, Silverman JL, Pessah IN, and Lein PJ (2019) Genetic mutations in $\mathrm{Ca}^{2+}$ signaling alter dendrite morphology and social approach in juvenile mice. Genes Brain Behav 18:e12526.

Kleiber M (1947) Body size and metabolic rate. Physiol Rev 27:511-541.

Klem GH, Lüders HO, Jasper HH, and Elger C (1999) The ten-twenty electrode system of the International Federation. The International Federation of Clinical Neurophysiology. Electroencephalogr Clin Neurophysiol Suppl 52:3-6.

Kochs E, Hoffman WE, Roewer N, and Schulte am Esch J (1990a) Alterations in brain electrical activity may indicate the onset of malignant hyperthermia in swine. Anesthesiology 73:1236-1242.

Kochs E, Hoffman WE, and Schulte am Esch J (1993) Improvement of brain electrical activity during treatment of porcine malignant hyperthermia with dantrolene. $\mathrm{Br}$ $J$ Anaesth 71:881-884.

Kochs E, Nollen H, and Schulte am Esch J (1990b) [Characteristics of cerebral blood flow and the electroencephalogram during experimental malignant hyperthermia]. Anasth Intensivther Notfallmed 25:348-353.

Korekar G, Kumar A, and Ugale C (2019) Occurrence, fate, persistence and remediation of caffeine: a review. Environ Sci Pollut Res Int DOI:10.1007/s11356 019-06998-8 [published ahead of print].

Kramer CY (1956) Extension of multiple range tests to group means with unequal numbers of replications. Biometrics 12:307-310.

Laird NM and Ware JH (1982) Random-effects models for longitudinal data. Biometrics 38:963-974.

Litman RS, Griggs SM, Dowling JJ, and Riazi S (2018) Malignant hyperthermia susceptibility and related diseases. Anesthesiology 128:159-167.

Lopez JR, Kaura V, Diggle CP, Hopkins PM, and Allen PD (2018) Malignant hyperthermia, environmental heat stress, and intracellular calcium dysregulation in a mouse model expressing the p.G2435R variant of RYR1. $\mathrm{Br} J$ Anaesth 121: 953-961.

McCarthy TV, Healy JM, Heffron JJ, Lehane M, Deufel T, Lehmann-Horn F, Farrall M, and Johnson K (1990) Localization of the malignant hyperthermia susceptibility locus to human chromosome 19q12-13.2. Nature 343:562-564.

Miller DM, Daly C, Aboelsaod EM, Gardner L, Hobson SJ, Riasat K, Shepherd S, Robinson RL, Bilmen JG, Gupta PK, et al. (2018) Genetic epidemiology of malignant hyperthermia in the UK. Br J Anaesth 121:944-952.

Mitchell DC, Knight CA, Hockenberry J, Teplansky R, and Hartman TJ (2014) Beverage caffeine intakes in the U.S. Food Chem Toxicol 63:136-142.

Mori F, Fukaya M, Abe H, Wakabayashi K, and Watanabe M (2000) Developmental changes in expression of the three ryanodine receptor mRNAs in the mouse brain. Neurosci Lett 285:57-60.

Nakai J, Dirksen RT, Nguyen HT, Pessah IN, Beam KG, and Allen PD (1996) Enhanced dihydropyridine receptor channel activity in the presence of ryanodine receptor. Nature 380:72-75.

Nehlig A, Daval JL, and Debry G (1992) Caffeine and the central nervous system: mechanisms of action, biochemical, metabolic and psychostimulant effects. Brain Res Brain Res Rev 17:139-170.

Noguchi KK, Johnson SA, Manzella FM, Masuoka KL, Williams SL, Martin LD, Dissen GA, Ikonomidou C, Schenning KJ, and Olney JW (2018) Caffeine Augments Anesthesia Neurotoxicity in the Fetal Macaque Brain. Sci Rep 8:5302, doi: 10.1038/ s41598-018-23560-7.

Palatini P, Ceolotto G, Ragazzo F, Dorigatti F, Saladini F, Papparella I, Mos L, Zanata G, and Santonastaso M (2009) CYP1A2 genotype modifies the association between coffee intake and the risk of hypertension. J Hypertens 27:1594-1601.

Pessah IN, Molinski TF, Meloy TD, Wong P, Buck ED, Allen PD, Mohr FC, and Mack MM (1997) Bastadins relate ryanodine-sensitive and -insensitive Ca2+ efflux pathways in skeletal SR and BC3H1 cells. Am J Physiol 272:C601-C614.
Phillis JW, Edstrom JP, Kostopoulos GK, and Kirkpatrick JR (1979) Effects of adenosine and adenine nucleotides on synaptic transmission in the cerebral cortex. Can J Physiol Pharmacol 57:1289-1312.

Rando TA and Blau HM (1994) Primary mouse myoblast purification, characterization, and transplantation for cell-mediated gene therapy. J Cell Biol 125 1275-1287.

Ratto D and Joyner RW (2019) Dantrolene, Statpearls, Treasure Island, FL.

Roberts MC, Mickelson JR, Patterson EE, Nelson TE, Armstrong PJ, Brunson DB, and Hogan K (2001) Autosomal dominant canine malignant hyperthermia is caused by a mutation in the gene encoding the skeletal muscle calcium release channel (RYR1). Anesthesiology 95:716-725.

Robinson RL, Anetseder MJ, Brancadoro V, van Broekhoven C, Carsana A, Censier K, Fortunato G, Girard T, Heytens L, Hopkins PM, et al. (2003) Recent advances in the diagnosis of malignant hyperthermia susceptibility: how confident can we be of genetic testing? Eur J Hum Genet 11:342-348.

Rosen GP, Escobar M, Fumero P, Viswanath O, and Wright J (2019) The importance of a prepared and ready malignant hyperthermia response team. J Clin Anesth 56:109-110.

Rosenberg H, Pollock N, Schiemann A, Bulger T, and Stowell K (2015) Malignant hyperthermia: a review. Orphanet J Rare Dis 10:93.

Rutkowsky JM, Knotts TA, Allen PD, Pessah IN, and Ramsey JJ (2020) Sex-specific alterations in whole body energetics and voluntary activity in heterozygous R163C malignant hyperthermia-susceptible mice. FASEB J 34:8721-8733.

Smith JM, Pearson S, and Marks V (1982) Plasma caffeine concentration in outpatients. Lancet 2:985-986.

Truong KM and Pessah IN (2019) Comparison of chlorantraniliprole and flubendiamide activity toward wild-type and malignant hyperthermia-susceptible ryanodine receptors and heat stress intolerance. Toxicol Sci 167:509-523.

Voermans NC, Snoeck M, and Jungbluth H (2016) RYR1-related rhabdomyolysis: a common but probably underdiagnosed manifestation of skeletal muscle ryanodine receptor dysfunction. Rev Neurol (Paris) 172:546-558.

Wayman GA, Yang D, Bose DD, Lesiak A, Ledoux V, Bruun D, Pessah IN, and Lein PJ (2012) PCB-95 promotes dendritic growth via ryanodine receptor-dependent mechanisms. Environ Health Perspect 120:997-1002.

Williams DC, Aleman M, Holliday TA, Fletcher D.J, Tharp B, Kass PH, Steffey EP, and LeCouteur RA (2008) Qualitative and quantitative characteristics of the electroencephalogram in normal horses during spontaneous drowsiness and sleep. $J$ Vet Intern Med 22:630-638.

Yang A, Palmer AA, and de Wit H (2010) Genetics of caffeine consumption and responses to caffeine. Psychopharmacology (Berl) 211:245-257.

Yang T, Riehl J, Esteve E, Matthaei KI, Goth S, Allen PD, Pessah IN, and Lopez JR (2006) Pharmacologic and functional characterization of malignant hyperthermia in the R163C RyR1 knock-in mouse. Anesthesiology 105:1164-1175.

Yuen B, Boncompagni S, Feng W, Yang T, Lopez JR, Matthaei KI, Goth SR, Protas F, Franzini-Armstrong C, Allen PD, et al. (2012) Mice expressing T4826I-RYR1 are viable but exhibit sex- and genotype-dependent susceptibility to malignant hyperthermia and muscle damage. FASEB $J$ 26:1311-1322.

Zhou A and Hyppönen E (2019) Long-term coffee consumption, caffeine metabolism genetics, and risk of cardiovascular disease: a prospective analysis of up to 347,077 individuals and 8368 cases. Am J Clin Nutr 109:509-516.

Zhou J, Bose D, Allen PD, and Pessah IN (2014) Malignant Hyperthermia and Other Related Disorders, Elsevier Health Sciences, New York, Philadelphia, PA.

Address correspondence to: Dr. Isaac N. Pessah, Molecular Biosciences, School of Veterinary Medicine, University of California, Davis, CA 95616. E-mail: inpessah@ucdavis.edu; or Dr. Monica Aleman, Departments of Medicine and Epidemiology, School of Veterinary Medicine, University of California, Davis CA 95616. E-mail: mraleman@ucdavis.edu 